\title{
Improved slant column density retrieval of nitrogen dioxide and formaldehyde for OMI and GOME-2A from QA4ECV: intercomparison, uncertainty characterisation, and trends
}

\author{
Marina Zara $^{1}$, K. Folkert Boersma ${ }^{1,2}$, Isabelle De Smedt ${ }^{3}$, Andreas Richter ${ }^{4}$, Enno Peters ${ }^{4}$, Jos H. G. M. van Geffen ${ }^{1}$, \\ Steffen Beirle ${ }^{5}$, Thomas Wagner ${ }^{5}$, Michel Van Roozendael ${ }^{3}$, Sergey Marchenko ${ }^{6}$, Lok N. Lamsal ${ }^{6}$, and Henk J. Eskes ${ }^{1}$ \\ ${ }^{1}$ Royal Netherlands Meteorological Institute, KNMI, De Bilt, the Netherlands \\ ${ }^{2}$ Wageningen University, WUR, Meteorology and Air Quality Group, Wageningen, the Netherlands \\ ${ }^{3}$ Institut royal d'Aéronomie Spatiale de Belgique, BIRA-IASB, Brussels, Belgium \\ ${ }^{4}$ Institut für Umweltphysik, IUP, Bremen, Germany \\ ${ }^{5}$ Max-Planck-Institut für Chemie, MPI, Mainz, Germany \\ ${ }^{6}$ Goddard Space Flight Center, NASA, Greenbelt, USA
}

Correspondence: Marina Zara (zara@knmi.nl)

Received: 13 December 2017 - Discussion started: 11 January 2018

Revised: 11 June 2018 - Accepted: 12 June 2018 - Published: 11 July 2018

\begin{abstract}
Nitrogen dioxide $\left(\mathrm{NO}_{2}\right)$ and formaldehyde (HCHO) column data from satellite instruments are used for air quality and climate studies. Both $\mathrm{NO}_{2}$ and $\mathrm{HCHO}$ have been identified as precursors to the ozone $\left(\mathrm{O}_{3}\right)$ and aerosol essential climate variables, and it is essential to quantify and characterise their uncertainties. Here we present an intercomparison of $\mathrm{NO}_{2}$ and $\mathrm{HCHO}$ slant column density (SCD) retrievals from four different research groups (BIRA-IASB, IUP Bremen, and KNMI as part of the Quality Assurance for Essential Climate Variables (QA4ECV) project consortium, and NASA) and from the OMI and GOME-2A instruments. Our evaluation is motivated by recent improvements in differential optical absorption spectroscopy (DOAS) fitting techniques and by the desire to provide a fully traceable uncertainty budget for the climate data record generated within QA4ECV. The improved $\mathrm{NO}_{2}$ and $\mathrm{HCHO} \mathrm{SCD}$ values are in close agreement but with substantial differences in the reported uncertainties between groups and instruments. To check the DOAS uncertainties, we use an independent estimate based on the spatial variability of the SCDs within a remote region. For $\mathrm{NO}_{2}$, we find the smallest uncertainties from the new QA4ECV retrieval $\left(0.8 \times 10^{15}\right.$ molec. $\mathrm{cm}^{-2}$ for both instruments over their mission lifetimes). Relative to earlier approaches, the QA4ECV NO 2 retrieval shows better agreement between DOAS and statistical uncertainty estimates, suggesting that the improved QA4ECV NO 2 retrieval
\end{abstract}

has reduced but not altogether eliminated systematic errors in the fitting approach. For $\mathrm{HCHO}$, we reach similar conclusions (QA4ECV uncertainties of 8-12 $\times 10^{15}$ molec. $\mathrm{cm}^{-2}$ ), but the closeness between the DOAS and statistical uncertainty estimates suggests that $\mathrm{HCHO}$ uncertainties are indeed dominated by random noise from the satellite's level 1 data. We find that SCD uncertainties are smallest for high top-of-atmosphere reflectance levels with high measurement signal-to-noise ratios. From 2005 to 2015, OMI NO $\mathrm{NCD}_{2}$ uncertainties increase by $1-2 \%$ year $^{-1}$, which is related to detector degradation and stripes, but OMI HCHO SCD uncertainties are remarkably stable (increase $<1 \%$ year $^{-1}$ ) and this is related to the use of Earth radiance reference spectra which reduces stripes. For GOME-2A, $\mathrm{NO}_{2}$ and $\mathrm{HCHO}$ SCD uncertainties increased by 7-9 and $11-15 \%$ year $^{-1}$ respectively up until September 2009, when heating of the instrument markedly reduced further throughput loss, stabilising the degradation of SCD uncertainty to $<3 \%$ year $^{-1}$ for 2009-2015. Our work suggests that the $\mathrm{NO}_{2} \mathrm{SCD}$ uncertainty largely consists of a random component $(\sim 65 \%$ of the total uncertainty) as a result of the propagation of measurement noise but also of a substantial systematic component ( $\sim 35 \%$ of the total uncertainty) mainly from "stripe effects". Averaging over multiple pixels in space and/or time can significantly reduce the SCD uncertainties. This suggests that trend detection in OMI, GOME-2 $\mathrm{NO}_{2}$, and $\mathrm{HCHO}$ time 
series is not limited by the spectral fitting but rather by the adequacy of assumptions on the atmospheric state in the later air mass factor (AMF) calculation step.

\section{Introduction}

Nitrogen oxides $\left(\mathrm{NO}_{x}=\mathrm{NO}+\mathrm{NO}_{2}\right)$ and formaldehyde (HCHO) play important roles in atmospheric chemistry by driving the formation of ozone $\left(\mathrm{O}_{3}\right)$ (e.g. Sillman et al., 1990) and aerosols (e.g. Bauer et al., 2007), and influencing hydroxyl $(\mathrm{OH})$ concentrations in the global troposphere (e.g. Miyazaki et al., 2017). Surface atmospheric concentrations of nitrogen dioxide $\left(\mathrm{NO}_{2}\right)$ may reach levels that are directly harmful to health (e.g. Fischer et al., 2015) and lead to detrimental environmental impacts through acid rain. $\mathrm{HCHO}$ is a known carcinogen (e.g. Zhu et al., 2017). Observations of $\mathrm{NO}_{2}$ and $\mathrm{HCHO}$ are thus important for air-quality monitoring and forecasting as well as climate (IPCC, 2013). Recently, the Global Climate Observation System (GCOS) has identified $\mathrm{NO}_{2}$ and $\mathrm{HCHO}$ as precursors to essential climate variables (ECVs) because of their value in detecting and attributing changes in $\mathrm{O}_{3}$ (e.g. Verstraeten et al., 2015) and aerosol distributions (GCOS-138, 2010).

Satellite instruments are providing long-term global records of tropospheric $\mathrm{NO}_{2}$ and $\mathrm{HCHO}$ column densities, as well as stratospheric $\mathrm{NO}_{2}$, but there is a need still for reliable and traceable information on data quality. The EU FP7 project Quality Assurance for Essential Climate Variables (QA4ECV) (http://www.qa4ecv.eu/, last access: 10 June 2018) is addressing this need by making a fully traceable quality assurance effort on all aspects of the $\mathrm{NO}_{2}$ and HCHO (and carbon monoxide) retrieval algorithms. Spectral fitting is the first step in the algorithms used for the retrieval of $\mathrm{NO}_{2}$ and $\mathrm{HCHO}$ columns (e.g. Leue et al., 2001; Richter et al., 2011; De Smedt et al., 2012). Using the differential optical absorption spectroscopy (DOAS) method, a modelled reflectance spectrum is matched to a satellite-measured reflectance spectrum to determine the abundance of $\mathrm{NO}_{2}$ and $\mathrm{HCHO}$ along the average photon path between the Sun and the satellite, called the slant column density (SCD) of the trace gas. The total SCD may consist of a tropospheric and a stratospheric part. In the second step of the retrieval, a separation of the two parts occurs. One procedure is via data assimilation in a chemistry transport model (CTM), which estimates the stratospheric $\mathrm{NO}_{2}$ vertical column density (VCD). Alternative approaches estimate the stratospheric column directly from the satellite total column measurements over remote regions and above mid-altitude clouds, without input from CTMs (Bucsela et al., 2013; Beirle et al., 2016). The stratospheric $\mathrm{NO}_{2} \mathrm{SCD}$ is then subtracted from the total SCD yielding the tropospheric $\mathrm{NO}_{2} \mathrm{SCD}$. In the final step the SCDs are converted to VCDs by dividing by the air mass factors (AMFs). An earlier study within the QA4ECV project focused on characterising and quantifying the uncertainties associated with the $\mathrm{NO}_{2}$ and $\mathrm{HCHO}$ AMF calculation (Lorente et al., 2017). Here, we quantify the uncertainties of state-of-science spectral fitting algorithms for the $\mathrm{NO}_{2}$ and HCHO SCDs from the Ozone Monitoring Instrument (OMI), aboard the EOS Aura satellite, and the Global Ozone Monitoring Experiment-2 (GOME-2) aboard the MetOp-A satellite.

Recently, spectral fitting procedures for $\mathrm{NO}_{2}$ have been revised to accommodate improved information on absorption cross sections, instrument calibration, and surface effects (Richter et al., 2011; Marchenko et al., 2015; Van Geffen et al., 2015; Anand et al., 2015; Krotkov et al., 2017). Based on extensive comparisons of spectral fitting approaches between BIRA-IASB, the University of Bremen (IUP), MPIC, and KNMI, the QA4ECV-consortium has developed improved spectral fitting algorithms for $\mathrm{NO}_{2}$ and $\mathrm{HCHO}$, which have been tested and applied to spectra from OMI, GOME-2A, SCIAMACHY, and GOME (QA4ECV Deliverable 4.2 in Muller et al., 2016; www.qa4ecv.eu). Here we will evaluate results from the new QA4ECV algorithm against existing SCD data sets, with special attention on characterising the uncertainties in the data sets.

The issue of slant column uncertainty ${ }^{1}$ remains relevant for $\mathrm{NO}_{2}$ retrievals because it dominates the overall retrieval uncertainty over low and moderately polluted areas (Boersma et al., 2004). For HCHO, SCD uncertainties are also substantial over regions with enhanced concentrations, and averaging multiple observations in time or over a larger area is required in order to bring the random fluctuations in the retrievals (e.g. Millet et al., 2008; Dufour et al., 2009) down to a level at which they can be used for applications such as trend analyses and emission estimates. Previous studies have quantified SCD uncertainties from GOME (Boersma et al., 2004), GOME-2 (Valks et al., 2011; De Smedt et al., 2012), and OMI (Boersma et al., 2007; Millet et al., 2008) for short periods of time, so it is unclear how the SCD uncertainties evolve over time, which is particularly relevant for instruments with substantial degradation in the quality of level 1 (ir)radiances such as GOME-2A (e.g. Dikty and Richter, 2011; Munro et al., 2016). Furthermore, the main drivers of the SCD uncertainties need to be identified to inform data users on where and when SCDs are most reliable

\footnotetext{
${ }^{1}$ Uncertainty is defined as a non-negative parameter that characterises the dispersion of values attributed to a measured quantity (e.g. SCD). There is also uncertainty associated with the method of measurement, as there can be other methods (i.e. different spectral fitting algorithms) that would give systematically different results of apparently equal validity. This definition follows the guidelines of the Guide to the Expression of Uncertainty in Measurement (GUM; https://www.bipm.org/utils/common/documents/ jcgm/JCGM_100_2008_E.pdf, last access: 10 June 2018) and the International Vocabulary of Basic and General Terms in Metrology (VIM; https://www.bipm.org/utils/common/documents/jcgm/ JCGM_200_2012.pdf, last access: 10 June 2018).
} 
and to what extent averaging or filtering is required to bring down retrieval noise to render the data useful for applications.

Our study on the quality assurance of $\mathrm{NO}_{2}$ and $\mathrm{HCHO}$ SCDs, therefore, has three coherent goals:

1. to evaluate $\mathrm{NO}_{2}$ and $\mathrm{HCHO}$ retrievals (from BIRAIASB, IUP, KNMI, NASA, QA4ECV) by quantifying and characterising the DOAS-derived SCDs and their uncertainties;

2. to investigate the dependencies of the DOAS-derived SCD uncertainties;

3. to analyse how SCD uncertainties develop over time, and how instrument degradation affects the stability of long-term climate data records.

The DOAS technique provides SCDs along with an uncertainty estimate for each spectral fit. The SCD uncertainties computed by DOAS are challenging to validate because direct independent reference measurements (of SCDs) are lacking. In principle, ground-based DOAS or SAOZ (Pommereau and Goutail, 1988) measurements can be used for validation, but they first require separate AMF conversions, corrections for mismatches in time, and careful consideration of differences in vertical and spatial representativeness of the satellite and ground-based measurements. In this paper, we therefore use an independent a posteriori method to establish the absolute level of the uncertainty in the $\mathrm{NO}_{2}$ and $\mathrm{HCHO}$ SCDs that can be attributed to instrument noise in the level 1 data from OMI and GOME-2. This technique, first used by Wenig et al. (2001) and later by Boersma et al. (2007), translates the spatial variability in the slant columns over confined pristine areas with known limited geophysical variability (Pacific Ocean) into an uncertainty estimate for the slant column itself. We concentrate on quality assurance of the most recent OMI and GOME-2 $\mathrm{NO}_{2} \mathrm{SCD}$ data sets from QA4ECV (QA4ECV Deliverable 4.2 in Muller et al., 2016), KNMI (Van Geffen et al., 2015), and NASA (Marchenko et al., 2015), and on OMI and GOME-2A HCHO from QA4ECV (Deliverable 4.2 in Muller et al., 2016) and BIRAIASB (De Smedt et al., 2012, 2015).

Section 2 introduces the OMI and GOME-2A instruments and discusses known issues with the quality of the level 1 data in the UV-VIS windows affecting the SCD uncertainties. Section 3 presents the currently operational spectral fitting algorithms for $\mathrm{NO}_{2}$ and $\mathrm{HCHO}$ retrievals, and the main differences between the fitting approaches from different groups. Section 4 presents the intercomparison of the absolute SCDs retrieved from all fitting algorithms. We describe our method for an independent a posteriori SCD uncertainty estimation, followed by the evaluation of the DOAS SCD uncertainty with the statistical method. This section also investigates dependencies of the SCD uncertainties on potential drivers such as the SCD itself, AMFs, cloud fractions or top-of-atmosphere reflectances. Additionally, a trend analysis of the SCD uncertainty derived from the DOAS and the statistical technique over the $2005-2015$ period is presented. We also discuss whether $\mathrm{NO}_{2}$ and $\mathrm{HCHO}$ retrievals from OMI and GOME-2 can meet the GCOS requirements (http://www.wmo.int/pages/prog/gcos/, last access: 10 June 2018) for satellite-based data products for climate, such as spatio-temporal resolution and instrumental stability. Finally, Sect. 5 summarises our findings and discusses directions for future research.

\section{Quality of level 1 data for UV-VIS sensors}

\subsection{Ozone Monitoring Instrument}

The Dutch-Finnish Ozone Monitoring Instrument (Levelt et al., 2006b) is a push-broom nadir-viewing near-UV-visible spectrometer aboard NASA's EOS Aura spacecraft launched in July 2004. In an ascending Sun-synchronous polar orbit, crossing the equator at 13:40 local time (LT), OMI provides measurements of various trace gases, $\mathrm{NO}_{2}$ and $\mathrm{HCHO}$ among them, along with ancillary information on UV-B surface flux, cloud and aerosol parameters. The instrument is equipped with two two-dimensional charge-coupled device (CCD) detectors (Dobber et al., 2006) for simultaneous spatial and spectral registration: CCD1 covers spectral channels UV1 (264-311 nm) and UV2 (307-383 nm) and CCD2 covers the VIS channel $(349-504 \mathrm{~nm})$. It is in the latter channel that the spectral features of $\mathrm{NO}_{2}$ are most prominent, while the UV2 channel is used for retrieving $\mathrm{HCHO}$ SCDs. With a spectral resolution (full width at half maximum) between 0.42 and $0.63 \mathrm{~nm}$ and a spatial resolution of $13 \times 24 \mathrm{~km}^{2}$ (along $\times$ across track) at nadir, OMI simultaneously measures the solar backscattered irradiance in a swath of $2600 \mathrm{~km}$ at every given orbital exposure, so that 60 pixels are simultaneously registered across track. OMI is equipped with a scrambler that depolarises the light entering the spectrometers. The instrument signal-to-noise ratio in the VIS and UV2 channels for clear-sky, dark scenes is such that the spectral fitting of typical differential absorption signatures is possible for $\mathrm{NO}_{2}$ (absorption signatures comparable to noise in the reflectances) and challenging for HCHO (absorption signatures weaker than noise by one order of magnitude; see Table 1).

Since the beginning of the OMI mission, non-physical variations in SCD values from one viewing angle (i.e. at a given cross-track position, or OMI "row" hereafter) relative to another have been observed in both the $\mathrm{NO}_{2}$ and $\mathrm{HCHO}$ data. These small, discrete jumps result in "stripes" along the orbit. The origin of the stripes is not well known, but it is probably related to small differences in wavelength calibration for each of the 60 viewing angles, and to noise and instrument-related artefacts (e.g. the relatively low-amplitude spectral features introduced by the solar diffuser) in the solar irradiance spectrum used in the compu- 
Table 1. Estimated signal-to-noise ratio (SNR) for OMI and GOME-2A in the UV and VIS channels for 1 pixel. The uncertainties in the logarithm of the reflectances are based on the SNR for the radiance and a relatively dark, clear-sky planetary scene with a TOA reflectance assumed to be 0.2 (or $0.8 \times 10^{13}$ photons sr${ }^{-1} \mathrm{~s}^{-1} \mathrm{~nm}^{-1} \mathrm{~cm}^{-2}$ ) for the UV2 channel and $0.1\left(1.3 \times 10^{13} \mathrm{photons} \mathrm{sr}^{-1} \mathrm{~s}^{-1} \mathrm{~nm}^{-1} \mathrm{~cm}^{-2}\right.$ ) for the VIS channel. The differential optical thickness was calculated for a scenario with $10 \times 10^{15} \mathrm{molec}^{\mathrm{cm}} \mathrm{cm}^{-2} \mathrm{HCHO}$ and $10 \times 10^{15}$ molec. $\mathrm{cm}^{-2} \mathrm{NO}_{2}$ and a total AMF of 4 .

\begin{tabular}{lrrrrrr}
\hline & $\begin{array}{r}\text { SNR radiances } \\
340-360 \mathrm{~nm}\end{array}$ & $\begin{array}{r}\text { Noise on } \\
\ln \left(I / I_{0}\right)\end{array}$ & $\begin{array}{r}\text { Differential optical } \\
\text { thickness HCHO }\end{array}$ & $\begin{array}{r}\text { SNR radiances } \\
400-470 \mathrm{~nm}\end{array}$ & $\begin{array}{r}\text { Noise on } \\
\ln \left(I / I_{0}\right)\end{array}$ & $\begin{array}{r}\text { Differential optical } \\
\text { thickness } \mathrm{NO}_{2}\end{array}$ \\
\hline OMI & $400^{\mathrm{a}}$ & $2.5 \times 10^{-3}$ & $3 \times 10^{-4}$ & $500^{\mathrm{a}}$ & $2 \times 10^{-3}$ & $2 \times 10^{-3}$ \\
GOME-2A & $1000^{\mathrm{b}}$ & $1 \times 10^{-3}$ & $3 \times 10^{-4}$ & $1000^{\mathrm{b}}$ & $1 \times 10^{-3}$ & $2 \times 10^{-3}$ \\
\hline
\end{tabular}

a Based on globally averaged OMI level 1 radiance SNR levels recorded for orbit 21078 (1 July 2008) (Quintus Kleipool, personal communication, 2017). The SNRs in the OMI irradiance (reference spectra used for retrievals, e.g. yearly averages in the OMNO2A v1, v2 approach) are much higher, 2000 for UV2 and 4000 for VIS, that it is neglected in the calculation of the uncertainty of the logarithm of the reflectance.

$\mathrm{b}$ This estimate (for 2007) is based on the level 1 radiance levels mentioned in the Table caption and signal-to-noise vs. level 1 curves for GOME-2A Band 4 and Band 5 obtained from Ruediger Lang (personal communication, 2017).

tation of the reflectance (Boersma et al., 2011; Veihelmann and Kleipool, 2006; Nico Rozemeijer, personal communication, 2017). Stripes appear as a systematic effect along the orbit, and it is possible to correct for them following an a posteriori "de-striping" procedure that is based on the premise that geophysical variation in $\mathrm{NO}_{2}$ or $\mathrm{HCHO}$ in the across-track direction (east-west) is smooth rather than stripe-like (Boersma et al., 2007). The $\mathrm{NO}_{2}$ de-striping corrections (for the OMNO2A retrievals in the DOMINO $\mathrm{v} 2$ processing system) are generally of the order of $0.3-$ $0.5 \times 10^{15}$ molec. $\mathrm{cm}^{-2}$, which is within $10 \%$ of typical SCD values, but have grown in time (Boersma et al., 2011). Weaker absorbers like HCHO are affected more by this instrumental artefact (up to $50 \times 10^{15}$ molec. $\mathrm{cm}^{-2}$ ), but the use of daily radiance spectra as a reference (instead of solar irradiance spectra) reduces the stripes in the OMI HCHO SCDs (down to $2 \times 10^{15}$ molec. $\mathrm{cm}^{-2}$ ) (e.g. De Smedt et al., 2015).

Apart from the stripes, OMI measurements contend with the row anomaly (RA), a dynamic effect first noticed in June 2007 when several cross-track FOVs (rows) began to experience partial blockage of incoming Earth radiance. Since then, the RA extended to other rows (https://disc.sci. gsfc.nasa.gov/Aura/data-holdings/OMI, last access: 10 June 2018; see more discussion in Schenkeveld et al., 2017). This RA mostly appears as a signal suppression in the level 1B radiance data at all wavelengths, leading to cloud retrievals of poor quality, even though successful spectral fits for $\mathrm{NO}_{2}$ and HCHO can still be achieved (QA4ECV Deliverable 4.2 in Muller et al., 2016). We exclude the affected rows 22-53 (0-based) from the entire orbit throughout the 2005-2015 period from our analysis.

In spite of the above issues, OMI's radiometric stability is very good for a UV-VIS spectrometer. It is monitored by routine measurements of solar flux and by tracking on-board parameters (Dobber et al., 2008) and geophysical parameters (e.g. average reflectivity in Antarctica and Greenland) (McPeters et al., 2015). Over the period 2004-2010 the optical degradation in the visible channel was less than $2 \%$
(Boersma et al., 2011) and remains below $2 \%$ up to this day (see Sect. 4.3.1). Schenkeveld et al. (2017) report 1-2\% radiance (practically wavelength independent) and 3-8\% irradiance (slightly wavelength-dependent) degradation over the mission, and the wavelength calibration of the instrument remained stable to $0.005-0.020 \mathrm{~nm}$. OMI data are considered to be reliable and of good quality for the full mission thus far.

\subsection{Global Ozone Monitoring Experiment-2}

The Global Ozone Monitoring Experiment-2 (Callies et al., 2000) on board EUMETSAT's METOP-A satellite (GOME2A) was launched in October 2006 into a descending Sun-synchronous orbit, crossing the equator at 09:30LT. GOME-2A is a whisk-broom UV-visible spectrometer measuring solar irradiance and Earth radiance in the nadir swath with ground pixels of $40 \mathrm{~km}$ along track and $80 \mathrm{~km}$ across track using a scanning mirror to measure 24 scenes across the $1920 \mathrm{~km}$ wide swath, followed by eight larger $\left(40 \times 240 \mathrm{~km}^{2}\right)$ back-scan pixels. Near-global coverage is obtained daily with small gaps in the equatorial regions. GOME-2A records spectra in the range from 240 to $790 \mathrm{~nm}$ at a spectral resolution of $0.26-0.51 \mathrm{~nm}$, allowing the retrieval of the same atmospheric components as OMI, as well as Sun-induced fluorescence (e.g. Joiner et al., 2013; Sanders et al., 2016). Additionally, two polarisation components are retrieved with polarisation measurement devices (PMDs) at 30 broadband channels covering the full spectral range. From 15 July 2013 onwards, GOME-2A operates in tandem with its accompanying sensor GOME-2B (launched in September 2012) with a reduced swath of $960 \mathrm{~km}$ and pixels of $40 \times 40 \mathrm{~km}^{2}$ (Munro et al., 2016), motivated by the desire to monitor global air quality on a daily basis with the two sensors. The GOME-2A signal-to-noise ratio in band 4 (UV) and band 5 (VIS) was (initially) better than for OMI, so that spectral fitting of typical differential absorption signatures is quite feasible for $\mathrm{NO}_{2}$ (with a signature $\sim 2 \times$ stronger than the noise in reflectances), and possible for HCHO (absorp- 
tion signatures weaker than noise but of comparable magnitude still - see Table 1).

Since the GOME-2A launch, the quality of its level 1 data seriously degraded due to (1) instability of the instrument slit function (e.g. Dikty and Richter, 2011; De Smedt et al., 2012), (2) potential degradation in the reflectance noise because of solar diffuser degradation, (3) instrument throughput loss, and (4) polarisation spectral structures in the UV channel. All these potentially influence the spectral fitting of $\mathrm{HCHO}$ and $\mathrm{NO}_{2}$ in the GOME-2A measurements. We discuss these issues in more detail below, since they are important for understanding the uncertainties associated with the $\mathrm{HCHO}$ and $\mathrm{NO}_{2} \mathrm{SCD}$ retrievals from GOME-2A.

The GOME-2A slit function varies seasonally and fluctuations are larger in the UV than in the visible, with the width of the slit function narrowing over time (e.g. FWHM reductions of $8 \%$ at $359 \mathrm{~nm}$ and $6 \%$ at $429 \mathrm{~nm}$ between 2007 and 2015; e.g. Lacan and Lang, 2011; Dikty and Richter, 2011, De Smedt et al., 2012; Munro et al., 2016). These variations are mostly related to the thermal fluctuations of the GOME2A optical bench associated with seasonal and long-term changes in the solar irradiance (Munro et al., 2016). Changes to the slit function shape due to inhomogeneous slit illumination are not considered to be an issue due to the averaging effect caused by across-track scanning (Munro et al., 2016). The calibration of the GOME-2A solar irradiance measurements is different from that of the radiances, because the irradiances are reflected by the solar diffuser before arriving at the scan mirror. This additional optical component (relative to the radiance light path) implies that any inadequacies in the characterisation of the diffuser or changes during the mission lead to degradation of the reflectances. To avoid these issues, but also the degradation in radiances and in scan-angle-dependent calibration knowledge, radiance measurements over a reference location are used instead of irradiances for GOME-2A HCHO SCD retrievals (e.g. De Smedt et al., 2012).

The degradation of other optical components in the GOME-2A instrument resulted in a progressive wavelengthdependent loss of the instrument throughput. The throughput losses are more pronounced in the UV (around $20 \%$ year $^{-1}$ ) than in the visible $\left(10 \%\right.$ year $\left.^{-1}\right)$ (EUMETSAT: GOME-2 Throughput Degradation ESA Final Report, 2011). The main impact of the degradation on the DOAS retrievals is an increase in the noise due to throughput loss. EUMETSAT issued throughput tests in January and September 2009 in order to understand the mechanisms responsible for this degradation and define actions to control it. The second test caused an additional decrease in throughput of $25 \%$ in the UV and $10 \%$ in the visible relative to January 2007 but also stabilised GOME-2A degradation, with a reported degradation rate of $3 \%$ year $^{-1}$ for the UV channel and $1 \%$ year $^{-1}$ for the visible after September 2009. Based on knowledge of the signal strength loss, we expect the random uncertainties of the SCDs to increase with time throughout the mission, but es- pecially before September 2009. We will discuss this aspect further in Sect. 4.3.

\section{DOAS technique}

All retrievals in this work use the DOAS technique (Platt, 2017), which is based on the Lambert-Beer law, describing the attenuation of light passing through a medium. It determines the trace-gas concentrations integrated along the effective photon path in the atmosphere by identifying the relative depth of their characteristic absorption fingerprints. The technique discriminates the spectrally smooth component of radiation attenuation (e.g. from Rayleigh and Mie scattering, variable surface reflectance, spectrally changing instrument throughput) from the attenuation from molecular absorption, which has distinct spectral features. In DOAS, a highpass filter (nominally a low-order polynomial) of the spectra eliminates these broadband extinction processes. Also, reference spectra are included to describe the effects of rotational Raman scattering (the Ring effect). The observed signal that varies rapidly with wavelength is matched to a modelled spectrum based on reference spectra (i.e. lab-measured cross section spectra) of the trace gases of interest. For this purpose, a model spectrum is constructed that approximates the observed reflectance spectrum $\left(R_{\mathrm{obs}}(\lambda)=\frac{\pi I(\lambda)}{\mu_{0} I_{0}(\lambda)}\right.$ with $I(\lambda)$ the Earth radiance spectrum, $I_{0}(\lambda)$ the reference spectrum, usually from the Sun, and $\mu_{0}$ the cosine of the solar zenith angle ${ }^{2}$ ) or the natural logarithm of the observed reflectance spectrum, which is proportional to the optical depth $\left(\tau(\lambda)=\ln \left(\frac{I_{0}(\lambda)}{I(\lambda)}\right)\right)$. The DOAS-technique then minimises the differences between the modelled and the observed spectra within a pre-defined spectral or fitting window with optimal sensitivity to the absorber of interest (e.g. González et al., 2015; QA4ECV Deliverable 4.2 in Muller et al., 2016; Liu et al., 2016). Those coefficients that minimise the differences between the model and the observations are retained as slant column densities for a given trace-gas species. Minimisation of the differences between modelled and observed reflectances is usually called the intensity fit; between modelled and observed optical depths it is the optical depth fit.

\section{1 $\mathrm{NO}_{2}$ slant column density retrievals}

\subsubsection{OMI $\mathrm{NO}_{2}$ spectral fitting and SCDs}

Table 2 lists the most important retrieval specifics of six $\mathrm{NO}_{2}$ satellite data sets studied here.

\footnotetext{
${ }^{2}$ In OMNO2A and QA4ECV-QDOAS algorithms (see Sect. 3.1.1), the impact of the solar zenith angle at which the backscattered light is measured is taken into account in the viewing geometry (i.e. AMF) of the measurement and the polynomial in the fit (See Sect. 3.1.1). A successful fit can be achieved even when measurement occurs at $90^{\circ}$ solar zenith angle $\left(\mu_{0}=0\right)$ by using $R_{\mathrm{obs}}(\lambda)=\frac{I(\lambda)}{I_{0}(\lambda)}$ as observed spectra instead.
} 
Table 2. Satellite $\mathrm{NO}_{2}$ slant column density retrievals evaluated in this work.

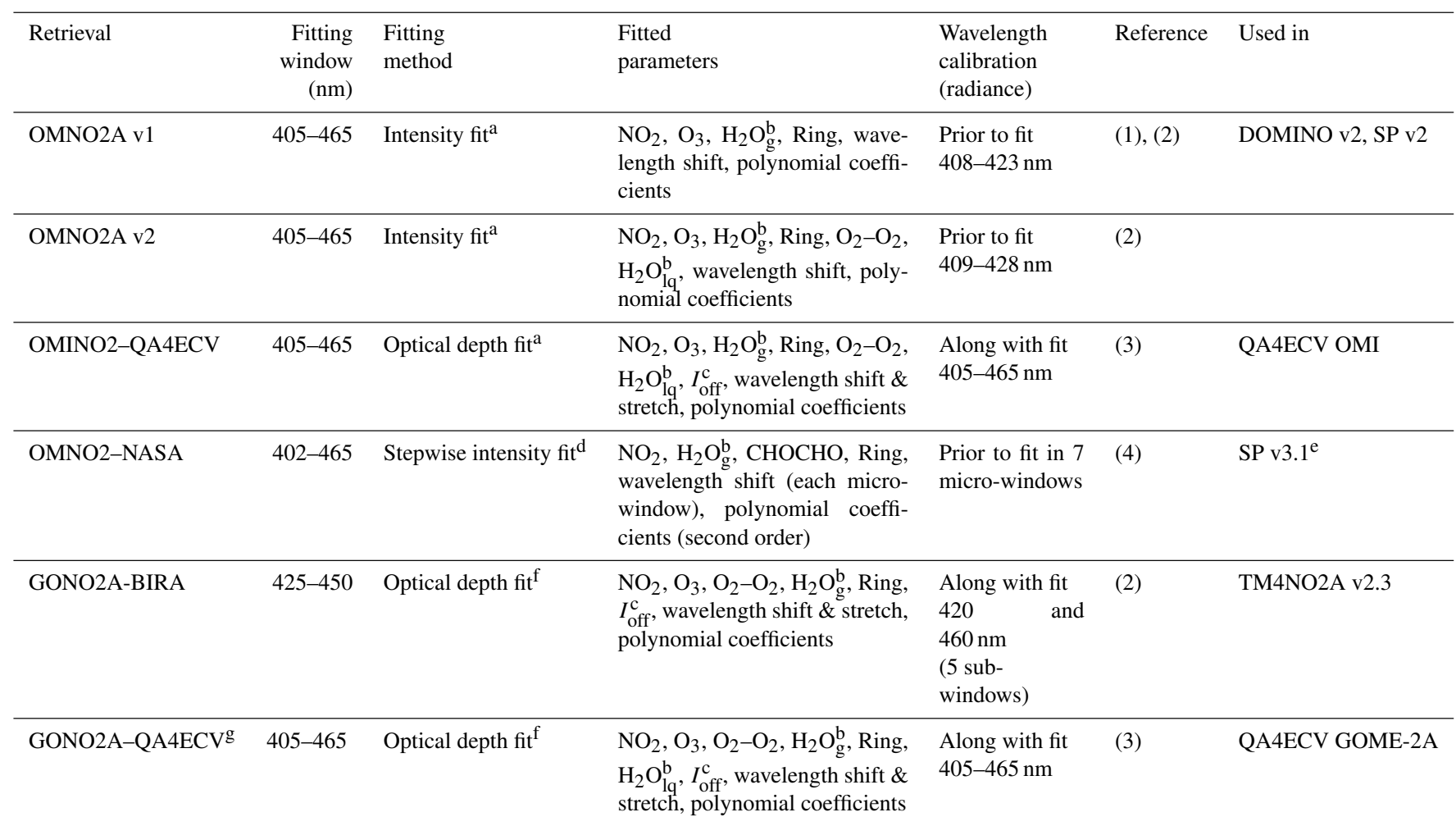

(1) Bucsela et al. (2006); (2) Van Geffen et al. (2015); (3) QA4ECV Deliverable 4.2 in Muller et al. (2016); (4) Marchenko et al. (2015); this is a reference to the revised spectral fitting algorithm of NO SCDs used in the Standard Product (SP) v3.0 (Krotkov et al., 2017), which is publicly available at https://disc.gsfc.nasa.gov/datasets/OMNO2_V003/summary/ (last access: 10 June 2018). In our study, we use an updated version (v3.1) (to be released) of $\mathrm{OMI} \mathrm{NO}_{2} \mathrm{SCDs}$ and their uncertainties.

a Annual average (2005) solar irradiance spectrum is used as the reference spectrum.

b Absorption cross sections of water vapour $\left(\mathrm{H}_{2} \mathrm{O}_{\mathrm{g}}\right)$ and liquid water $\left(\mathrm{H}_{2} \mathrm{O}_{\mathrm{lq}}\right)$ are used as fitted parameters. The interaction of pure liquid water (e.g. ocean) with incident solar radiation in the VIS (via absorption and vibrational Raman scattering) has an impact on scattered light measured over these areas affecting the DOAS retrievals (Peters et al., 2014).

${ }^{\mathrm{c}}$ The intensity offset, $I_{\text {off }}$, corrects for any additive amount of light (either real, i.e. stray light, or an instrumental artefact, i.e. dark current changes) that influences the estimation of the optical depth,

$\tau(\lambda)=\ln \left(\frac{I_{0}(\lambda)}{I(\lambda)}\right)$, with $I_{0}(\lambda)$ the solar irradiance spectrum and $I(\lambda)$ the Earth radiance (Peters et al., 2014).

$\mathrm{d}$ Monthly averaged solar irradiance spectrum is used as the reference spectrum.

e See reference (4)

${ }^{\mathrm{f}}$ Daily solar irradiance spectrum is used as the reference spectrum.

$\mathrm{g}$ The period 2007-2011 has been processed by IUP with NLIN software (Richter, 1997) and 2012-2015 by BIRA-IASB with QDOAS software (Danckaert et al., 2017) to share the burden of processing tasks. The intercomparison shows that they are very consistent (QA4ECV Deliverable 4.2 in Muller et al., 2016; Sect. 2.3.1).

In the OMNO2A v1 and v2 retrievals, the modelled spectrum is expressed in terms of reflectance (intensity), followed by a non-linear fit to the observed reflectances (intensity fit). The modelled reflectance used in OMNO2A v1 and v2 to minimise the fit residual $r(\lambda)$ with the observed $R_{\text {obs }}(\lambda)$ is

$$
\begin{aligned}
R_{\mathrm{mod}}=\frac{I(\lambda)}{I_{0}(\lambda)}= & P(\lambda) \cdot \exp \left[-\sum_{k=1}^{N_{k}} \sigma_{k}(\lambda) \cdot N_{\mathrm{s}}, k\right] \\
& \cdot\left(1+C_{\text {Ring }} \frac{I_{\text {Ring }}(\lambda)}{I_{0}(\lambda)}\right)+r(\lambda),
\end{aligned}
$$

with $I(\lambda)$ as the Earth radiance, $I_{0}(\lambda)$ as the 2005 annual average solar irradiance spectrum, and $\sigma_{k}(\lambda)$ as the trace-gas cross sections. The Ring effect, caused by inelastic Raman scattering of incoming sunlight by $\mathrm{N}_{2}$ and $\mathrm{O}_{2}$ molecules (Grainger and Ring, 1962), is accounted for by the term inside the parenthesis on the right-hand side of Eq. (1). Here, $C_{\text {Ring }}$ represents the Ring fitting coefficient and $I_{\text {Ring }}(\lambda) / I_{0}(\lambda)$ the Sun-normalised synthetic Ring spectrum. For usage in Eq. (1) $\sigma_{k}$ and $I_{\text {Ring }}$ have been convolved with the instrument slit function. This is different from many other fit models that include the Ring effect as a pseudo absorber, whereas in OMNO2A it is modelled as a source of photons influencing the backscattered contributions to the modelled reflectance. The radiance $I$ is wavelength calibrated prior to solving the above equation, while the irradiance $I_{0}$ is assumed to be well calibrated. All terms in Eq. (1) need to be given at the same wavelength grid: for OMNO2A the irradiance and the reference spectra are interpolated to the (calibrated) radiance wavelength grid. Fit parameters are the trace-gas slant columns $N_{\mathrm{s}, \mathrm{k}}$, the Ring effect coefficient $C_{\text {Ring }}$, and the coefficients $\alpha_{m}$ of the DOAS polynomial $P(\lambda)=\sum \alpha_{m} \lambda^{m}$ of order $m$. Note that Eq. (1) is fully non-linear due to the way the Ring effect is included on the right-hand side. OMNO2A v2 slant column retrievals are improved relative to $\mathrm{v} 1$ via an optimised window used for the 
prior-to-fit wavelength calibration, leading to much reduced fitting errors, and via the inclusion of the absorption by the $\mathrm{O}_{2}-\mathrm{O}_{2}$ collision complex and by liquid water $\left(\mathrm{H}_{2} \mathrm{O}_{\mathrm{lq}}\right)$ (Van Geffen et al., 2015).

The OMINO2-QA4ECV retrieval performs a $\chi^{2}$ minimisation of the residual $r(\lambda)$ using the QDOAS software (Danckaert et al., 2017) developed at BIRA-IASB, wherein the modelled spectrum is expressed in terms of optical depth, followed by a mostly linear fit to the observed optical depth (optical depth fit):

$$
\begin{aligned}
R_{\mathrm{mod}}^{*} & =\ln \left[\frac{I\left(\lambda^{\prime}\right)-P_{\mathrm{off}}\left(\lambda^{\prime}\right)}{I_{0}(\lambda)}\right] \\
& =P^{*}(\lambda)-\sum_{k=1}^{N_{k}} \sigma_{k}(\lambda) \cdot N_{\mathrm{s}, \mathrm{k}}^{*}-\sigma_{\text {Ring }}(\lambda) \cdot C_{\mathrm{Ring}}^{*}+r^{*}(\lambda),
\end{aligned}
$$

with $P_{\text {off }}(\lambda)$ a first-order polynomial $P_{\text {off }}(\lambda)=c_{0}+c_{1} \cdot \lambda$ that describes the intensity offset correction (denoted as $I_{\text {off }}$ in Table 2$)$, and $\lambda^{\prime}=\lambda_{I}+\omega_{q} \cdot\left(\lambda_{I}-\lambda_{0}\right)+\omega_{\mathrm{s}}$ the calibrated radiance wavelength grid, with $\lambda_{I}$ the input radiance wavelength grid, $\omega_{\mathrm{s}}$ a wavelength shift with respect to the wavelength $\lambda_{0}$ of the centre of the fit window, and $\omega_{q}$ a stretch $\left(\omega_{q}>0\right)$ or squeeze $\left(\omega_{q}<0\right)$ term. Note that the fit parameters on the left side of Eq. (2), the wavelength calibration and intensity offset correction, constitute non-linear terms of the linear fit. All terms in Eq. (2) need to be given at the same wavelength grid: for QDOAS the calibrated $\lambda^{\prime}$ and the reference spectra are interpolated to the irradiance wavelength grid, calibrated before the fit using a high-resolution solar spectrum (Fraunhofer calibration). Fit parameters are the tracegas slant columns $N_{\mathrm{s}, \mathrm{k}}^{*}$, the Ring effect coefficient $C_{\mathrm{Ring}}^{*}$, the coefficients $\alpha_{m}^{*}$ of the DOAS polynomial $P^{*}$, the coefficients $c_{\mathrm{i}}$ of the intensity offset polynomial $P_{\text {off }}$, and the wavelength calibration coefficients $\omega_{\mathrm{s}}$ and $\omega_{q}$. The polynomials $P(\lambda)$ and $P^{*}(\lambda)$ effectively act as the high-pass filter mentioned in the description of the DOAS technique above. The coefficient $c_{\mathrm{i}}$ represents the offset parameter that accounts for instrumental effects like stray light inside the spectrometer, instrumental thermal instabilities, changes in the detector's dark current, wavelength shifts between $I$ and $I_{0}$ or other remaining calibration issues in the level 1 product which are known to be sources of bias in DOAS retrievals of minor trace species. It may also account for atmospheric effects such as incomplete removal of Ring structures (De Smedt et al., 2008; Coburn et al., 2011; Peters et al., 2014; QA4ECV Deliverable 4.2 in Muller et al., 2016).

The $\chi^{2}$ merit function of the non-linear fit of Eq. (1) is defined by

$\chi^{2}=\sum_{i=1}^{N_{\lambda}}\left(\frac{r\left(\lambda_{\mathrm{i}}\right)}{\Delta\left(I\left(\lambda_{\mathrm{i}}\right) / I_{0}\left(\lambda_{\mathrm{i}}\right)\right)}\right)^{2}$,

with $N_{\lambda}$ the number of wavelengths $\lambda_{\mathrm{i}}$ in the fit interval and $\Delta\left(I / I_{0}\right)$ the standard error on the measurement. In case of the mostly linear fit of Eq. (2) as performed in OMINO2QA4ECV the residual is not weighted with the error on the measurement, so that the $\chi^{2}$ merit function is simply given by

$\chi^{2}=\sum_{i=1}^{N_{\lambda}}\left(r\left(\lambda_{\mathrm{i}}\right)\right)^{2}$

The magnitude of $\chi^{2}$ is a measure for how good the fit is. We discuss DOAS SCD uncertainties in more detail in Sect. 4.1.2.

The OMNO2-NASA algorithm (used in NASA SP v3) uses the intensity fit (Eq. 1) as a default ${ }^{3}$ along with monthlyaveraged irradiances. The algorithm is different from the OMNO2A and OMINO2-QA4ECV approaches in that it uses a step-by-step (iterative) rather than a simultaneous fitting procedure, wherein a reflectance spectrum is optimised for $\mathrm{NO}_{2}$ fitting. In the first step, seven small fitting windows (micro-windows) are used for iterative wavelength adjustments combined with (window-by-window) removal of the Ring patterns and low-order polynomial smoothing. Wherever appropriate, OMNO2-NASA uses a combination of atmospheric and water-leaving Ring spectra in the $C_{\text {Ring }}(\lambda)$ estimates. In this iterative process the irradiances are eventually mapped onto the radiance wavelength grid. Then, in step 2 the $\mathrm{NO}_{2}, \mathrm{H}_{2} \mathrm{O}$, and CHOCHO SCDs are sequentially determined in the preliminary spectral regions specifically chosen for the given trace-gas retrieval. After removal of these tracegas absorption features and a thorough evaluation and iterative removal of instrument noise, the final SCDs are obtained via a similar sequential retrieval in slightly adjusted, broad spectral windows optimal for a given trace-gas species (e.g. $402-465 \mathrm{~nm}$ for $\mathrm{NO}_{2}$ ).

All four OMI fitting approaches convolve high-resolution absorption cross section spectra with the OMI slit function (Dirksen et al., 2006; this pre-flight slit function is slightly modified to match the observed irradiances in OMNO2NASA), which has proved to be stable throughout the OMI mission period (Schenkeveld et al., 2017; Sun et al., 2017). OMNO2A v1 uses a fixed slit function for all 60 rows, where in OMNO2A v2 the slit function has been updated with respect to OMNO2A v1 to better represent the across-track average (Van Geffen et al., 2015). In the OMINO2-QA4ECV and OMNO2-NASA algorithms, the cross section spectra have been convolved for each of the 60 across-track positions individually.

\subsubsection{GOME-2A NO 2 SCDs}

The GONO2A-BIRA spectral fits are performed using the QDOAS software developed at BIRA-IASB, which solves

\footnotetext{
${ }^{3}$ When the intensity fitting approach fails (e.g. yields negative slant columns), the optical depth is modelled (Eq. 2) instead of the reflectances. If optical depth fitting also fails, then the solution from the intensity fit is provided as is.
} 
Table 3. Satellite HCHO slant column density retrievals evaluated in this work.

\begin{tabular}{|c|c|c|c|c|c|}
\hline Retrieval & $\begin{array}{r}\text { Fitting } \\
\text { window }(\mathrm{nm})\end{array}$ & $\begin{array}{l}\text { Fitting } \\
\text { method }\end{array}$ & $\begin{array}{l}\text { Fitted } \\
\text { parameters }\end{array}$ & $\begin{array}{l}\text { Wavelength } \\
\text { calibration } \\
\text { (radiance) }\end{array}$ & Reference \\
\hline OMIHCHO-QA4ECV & $328.5-359.0$ & Optical depth fit ${ }^{\mathrm{e}}$ & $\begin{array}{l}\mathrm{HCHO}, \mathrm{O}_{3}(223 \text { and } 243 \mathrm{~K}), \mathrm{BrO}, \\
\mathrm{NO}_{2}, \mathrm{O}_{2}-\mathrm{O}_{2}, \mathrm{Ring}, \mathrm{O}_{3} \mathrm{~L}^{\mathrm{d}}, \mathrm{O}_{3} \mathrm{O}_{3}^{\mathrm{d}}, I_{\mathrm{off}} \text {, } \\
\text { wavelength shift \& stretch, polynomial } \\
\text { coefficients }\end{array}$ & $\begin{array}{l}\text { Along with fit } \\
325-360 \mathrm{~nm}\end{array}$ & (2) \\
\hline GO2AHCHO-BIRA & $328.5-346.0$ & Optical depth fit ${ }^{\mathrm{a}}$ & $\begin{array}{l}\mathrm{HCHO}(297 \mathrm{~K}), \mathrm{O}_{3}(228 \text { and } 243 \mathrm{~K}) \text {, } \\
\mathrm{BrO}\left(223 \mathrm{~K}, \text { pre-fitted }{ }^{\mathrm{b}}\right), \mathrm{NO}_{2}(220 \mathrm{~K}) \text {, } \\
\mathrm{O}_{2}-\mathrm{O}_{2}\left(293 \mathrm{~K}, \text { pre-fitted }^{\mathrm{b}}\right), \mathrm{Ring}^{\mathrm{c}} \text {, } \\
\text { Ring2 }^{\mathrm{c}}, \mathrm{O}_{3} \mathrm{~L}^{\mathrm{d}}, \mathrm{O}_{3} \mathrm{O}_{3}^{\mathrm{d}}, I_{\mathrm{off}}, \text { Eta and zeta } \\
\text { polarisation vectors, wavelength shift \& } \\
\text { stretch, polynomial coefficients }\end{array}$ & $\begin{array}{l}\text { Along with fit } \\
325-360 \mathrm{~nm} \\
(5 \text { sub- } \\
\text { windows })\end{array}$ & (1) \\
\hline GO2AHCHO-QA4ECV & $328.5-359.0$ & Optical depth fit ${ }^{\mathrm{e}}$ & $\begin{array}{l}\mathrm{HCHO}, \mathrm{O}_{3}(223 \text { and } 243 \mathrm{~K}), \mathrm{BrO} \text {, } \\
\mathrm{NO}_{2}, \mathrm{O}_{2}-\mathrm{O}_{2}, \text { Ring, } \mathrm{O}_{3} \mathrm{~L}^{\mathrm{d}}, \mathrm{O}_{3} \mathrm{O}_{3}^{\mathrm{d}} \text {, } \\
I_{\text {off }} \text { Eta and zeta polarisation vectors, } \\
\text { pseudo cross section to correct for East- } \\
\text { West bias, wavelength shift \& stretch, } \\
\text { polynomial coefficients }\end{array}$ & $\begin{array}{l}\text { Along with fit } \\
325-360 \mathrm{~nm}\end{array}$ & (2) \\
\hline
\end{tabular}

(1) De Smedt et al. (2015); (2) QA4ECV Deliverable 4.2 in Muller et al. (2016).

${ }^{\mathrm{a}}$ Instead of a solar irradiance spectrum, daily Earth radiance spectra over the equatorial Pacific $\left(15^{\circ} \mathrm{S}-15^{\circ} \mathrm{N}, 180-240^{\circ} \mathrm{E}\right)$ are used as the reference spectrum.

${ }^{\mathrm{b}} \mathrm{BrO}$ and $\mathrm{O}_{4}$ are pre-fitted in the 328.5-359 and 339-364 nm wavelength intervals respectively. The resulting SCD in each case is used as a fixed value in the nominal window of

$328.5-346.0 \mathrm{~nm}$.

c Two cross sections are used to account for the Ring effect (Vountas et al., 1998), calculated in an ozone-containing atmosphere for low and high SZA (solar zenith angle) using LIDORT RRS (Spurr et al., 2008).

d Two additional terms $\left(\mathrm{O}_{3} \mathrm{~L}\right.$ and $\left.\mathrm{O}_{3} \mathrm{O}_{3}\right)$ are included to better cope with strong $\mathrm{O}_{3}$ absorption effects (Puksite et al., 2010; De Smedt et al., 2012). They result from the Taylor expansion of the $\mathrm{O}_{3}$ absorption as a function of the wavelength.

e Instead of a solar irradiance spectrum, daily Earth radiance spectra over the equatorial Pacific $\left(15^{\circ} \mathrm{S}-15^{\circ} \mathrm{N}, 150-250^{\circ} \mathrm{E}\right)$ are used as the reference spectrum.

Eq. (2). The GONO2A-BIRA algorithm uses the 425$450 \mathrm{~nm}$ window and fits the absorption cross sections of $\mathrm{NO}_{2}, \mathrm{O}_{3}, \mathrm{O}_{2}-\mathrm{O}_{2}$, and $\mathrm{H}_{2} \mathrm{O}_{\mathrm{g}}$. The fit also accounts for the Ring effect and includes an intensity offset, along with a third-order polynomial. The GONO2A-QA4ECV differs from the GONO2A-BIRA retrieval in the choice of a wider fitting window of $405-465 \mathrm{~nm}$ in the retrieval code and is largely identical to the approach taken in OMINO2QA4ECV. Both algorithms use daily solar reference spectrum, which contrasts with the use of a fixed annual average or monthly-averaged solar reference spectra in the OMI retrievals. Previous studies indicated that SCDs retrieved from the same sensor in the $405-465 \mathrm{~nm}$ window are approximately $0.5 \times 10^{15}$ molec. $\mathrm{cm}^{-2}$ higher than those retrieved from the $425-450 \mathrm{~nm}$ window (Van Geffen et al., 2015).

\subsection{HCHO slant column density retrievals}

Table 3 lists retrieval specifics of the $\mathrm{HCHO}$ satellite data sets from OMI and GOME-2A.
For OMI and GOME-2 HCHO retrievals, a dynamical convolution of the cross sections is performed along with the fit using the improved slit function derived prior to the fit, during the Fraunhofer calibration. The QA4ECV HCHO retrievals share many aspects with the QA4ECV spectral fitting for $\mathrm{NO}_{2}$. QA4ECV and BIRA HCHO SCD retrievals are also very similar in absorption cross sections and retrieval code used (QDOAS, solving Eq. 2). The most prominent differences between the QA4ECV and BIRA retrievals are the following.

1. Fitting windows: while the BIRA retrievals used a reduced fitting interval $(328.5-346.0 \mathrm{~nm})$ combined with pre-fits of $\mathrm{O}_{2}-\mathrm{O}_{2}$ and $\mathrm{BrO}$ slant columns in dedicated windows, the QA4ECV retrievals use a single extended fitting interval $(328.5-359.0 \mathrm{~nm})$. There is therefore no pre-fit of $\mathrm{O}_{2}-\mathrm{O}_{2}$ and $\mathrm{BrO}$ slant columns in QA4ECV. However, the switch to an extended fitting interval introduces additional retrieval difficulties for GOME-2, since this instrument suffers from polarisation structures not fully corrected by level $0-1$ processing lead- 

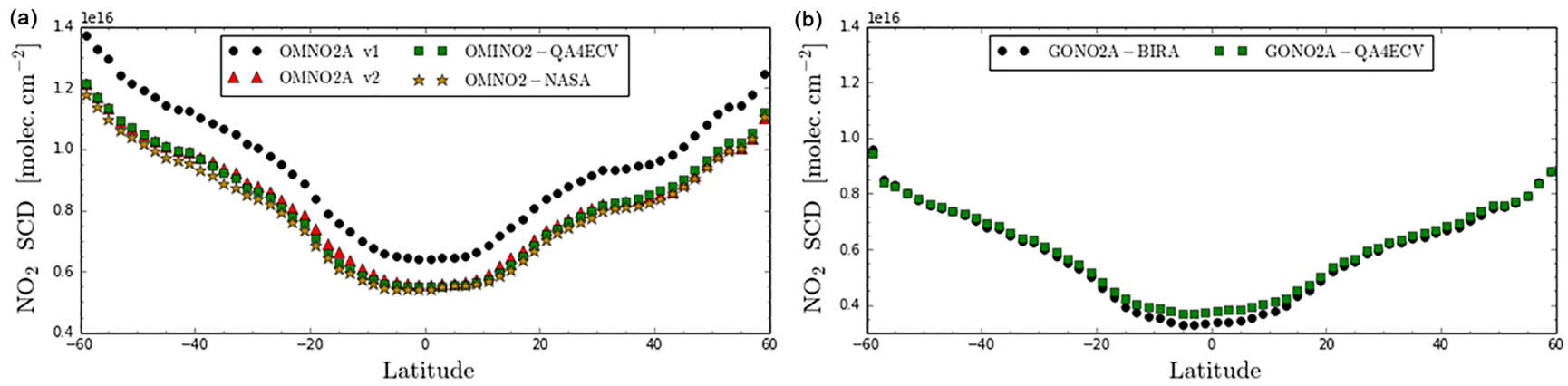

Figure 1. Average $\mathrm{NO}_{2}$ slant columns within $2^{\circ}$ wide latitudinal bins for OMNO2A v1 (black circles), OMNO2A v2 (red triangles), OMINO2-QA4ECV (green squares), and OMNO2-NASA (yellow stars) algorithms (a), and for GONO2A-BIRA (black circles) and GONO2A-QA4ECV (green squares) algorithms (b) for the Pacific (reference sector: $60^{\circ} \mathrm{N}-60^{\circ} \mathrm{S}$ and $150-180^{\circ} \mathrm{W}$ ) orbit from day 1 of January, April, July, and October (or closest available data) 2005-2015 for OMI and 2007-2015 for GOME-2A.

ing to scan-angle-dependent biases in HCHO. To mitigate these biases, polarisation response cross sections (eta and zeta) are added to the fit together with an empirical cross section derived from East/West mean fitting residuals (Richter et al., 2016). While successful in eliminating polarisation-related biases, these additional cross sections have a non-negligible impact on the retrieval noise and its time evolution (this issue is further illustrated in Sect. 4.1.5 and 4.3.3).

2. The Ring (pseudo) cross sections are now calculated following Chance and Spurr (1997) (previously Vountas et al., 1998, was used).

3. An improved earthshine reference selection scheme is implemented for GOME-2: Earth radiance spectra are now grouped along viewing zenith angle instead of one generic Earth radiance reference spectrum.

\section{Results and discussion}

\subsection{Quality assessment of $\mathrm{NO}_{2}$ and $\mathrm{HCHO}$ slant column densities}

\subsubsection{Slant column density intercomparisons}

We compare the $\mathrm{NO}_{2}$ SCDs from the OMNO2A v2, OMNO2-NASA, and OMINO2-QA4ECV algorithms, with OMNO2A v1. Figure 1a shows average absolute $\mathrm{NO}_{2} \mathrm{SCDs}$ as a function of latitude for all four OMI SCD products for unpolluted Pacific orbits from day 1 of January, April, July, and October 2005 up to 2015. The SCDs show lowest values in the tropics (shorter light path and lower VCDs), and higher values poleward. Averaged over all latitudes, the revised algorithms result in $12-15 \%$ lower SCDs (1.2$1.4 \times 10^{15}$ molec. $\mathrm{cm}^{-2}$ ) than OMNO2A v1 SCDs, in line with the reductions reported for OMNO2A v2 in Van Geffen et al. (2015). The revised OMNO2A v2, OMINO2QA4ECV, and OMNO2-NASA SCDs are in close agree- ment (differences $<4 \%$ ). The OMNO2-NASA SCDs (and their uncertainties) used in this analysis correspond to the latest version (v3.1; to be released) of the new Standard Product (SP) (Krotkov et al., 2017). Over the chosen clean-sector area the v3.1 SCDs are on average higher by $\sim 0.5 \times 10^{15}$ molec. $\mathrm{cm}^{-2}$ than v3.0. Differences between v3.1 and v3.0 SCD values are related to the changed approach to flagging the presumably noisy wavelength bins in the OMI radiances as well as improved solar reference spectra. The GOME-2A NO $\mathrm{NO}_{2}$ SCDs (Fig. 1b) are $\sim 2$ $3 \times 10^{15}$ molec. $\mathrm{cm}^{-2}$ lower than for OMI, which is anticipated because of the diurnal increase in stratospheric $\mathrm{NO}_{2}$ (e.g. Dirksen et al., 2011) and differences in viewing geometries. The GONO2A-QA4ECV SCDs are in line with GONO2A-BIRA, with the latter showing on average slightly lower values (by $<0.5 \times 10^{15}$ molec. $\mathrm{cm}^{-2}$ ), reflecting the similarity of the BIRA and QA4ECV algorithms. Their main differences are the choice of fitting window and that the $\mathrm{H}_{2} \mathrm{O}_{\text {lq }}$ is not fitted in the small fitting window (for GONO2ABIRA). Their relative difference is highest $(\sim 12 \%)$ around the Equator.

For HCHO, a comparison of SCDs is less straightforward than for $\mathrm{NO}_{2}$. First of all, daily Earth radiance spectra are used as a reference for the DOAS retrievals instead of solar irradiance spectra. The Earth radiance reference spectra are taken over a reference sector in the equatorial $\mathrm{Pa}$ cific, where $\mathrm{CH}_{4}$ oxidation is the only significant source of HCHO. The resulting (differential) HCHO SCDs may then have values close to zero, or even be negative, indicating that a scene has a similar or smaller HCHO amount than in the reference spectrum. After the fit, a background correction is applied to the SCDs (De Smedt et al., 2015). The final differential SCDs ( $\triangle \mathrm{SCDs}$ ) are the result of subtracting the mean HCHO SCD over each OMI row and by $5^{\circ}$ of latitude bins within the reference sector $\left(N_{\mathrm{s} 0}\right)$, from the SCDs $\left(N_{\mathrm{s}}\right)$ of the same day, $\Delta N_{\mathrm{s}}=N_{\mathrm{s}}-N_{\mathrm{s} 0}$ (QA4ECV Deliverable 4.2 in Muller et al., 2016; De Smedt et al., 2017a, 2018). This normalisation approach and the choice of daily 

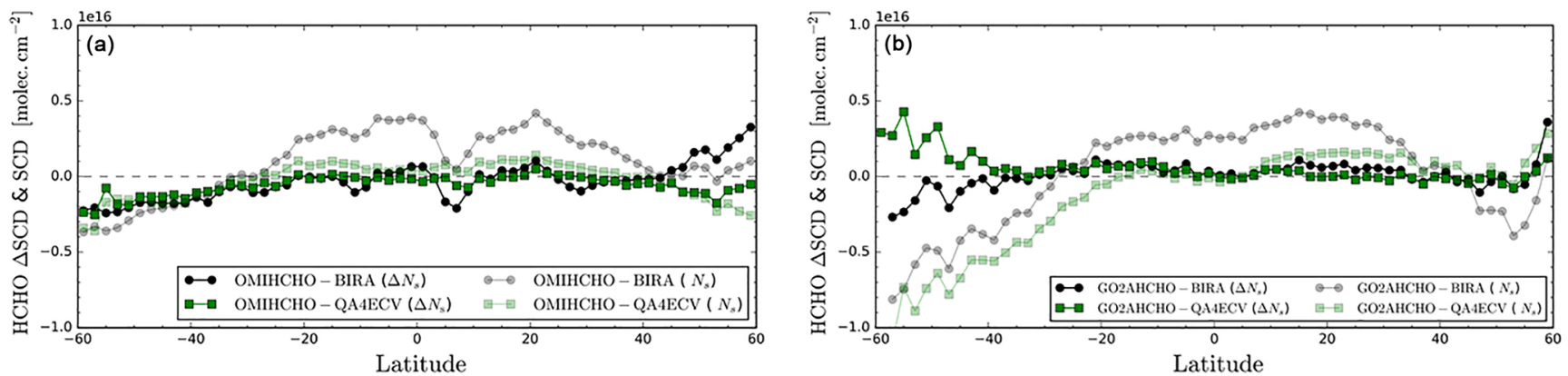

Figure 2. Average differential HCHO slant columns within $2^{\circ}$ wide latitudinal bins for (a) OMIHCHO-BIRA (black circles) and OMIHCHO-QA4ECV (green squares) for the Pacific $\left(60^{\circ} \mathrm{N}-60^{\circ} \mathrm{S}\right.$ and $\left.150-180^{\circ} \mathrm{W}\right)$ orbit from day 1 of January, April, July, and October (or closest available data) 2005-2015, and for (b) GO2AHCHO-BIRA (black circles) and GO2AHCHO-QA4ECV (green squares) for the Pacific orbits from day 1 of January up to December and from day 15 of January, April, July, and October (or closest available data) 2007-June 2014 and 2007-2015 respectively. The light grey and green lines represent the HCHO SCDs before the background correction.

radiance spectra results in $\triangle \mathrm{SCDs}$ close to zero over the reference region. Selecting daily Earth radiance reference spectra helps to reduce the effects of radiance degradation for GOME-2A retrievals and the effects of stripes for OMI. The final tropospheric $\mathrm{HCHO}$ vertical columns $\left(N_{\mathrm{v}}\right)$ are then defined as $N_{\mathrm{v}}=\frac{\Delta N_{\mathrm{s}}}{M}+\frac{M_{0}}{M} N_{\mathrm{v}, 0, \text { CTM }}$, where $M$ is the tropospheric AMF, and $M_{0}$ and $N_{\mathrm{v}, 0, \mathrm{CTM}}$ are respectively the AMF and the model background column in the reference sector.

Figure 2a shows a comparison of HCHO SCDs before (light lines) and after (dark lines) background correction from the OMIHCHO-QA4ECV and OMIHCHO-BIRA algorithms. Their differential SCDs ( $\triangle \mathrm{SCDs}$; dark green and black symbols) are highly consistent, with only a small difference of $\sim 0.7 \times 10^{15}$ molec. $\mathrm{cm}^{-2}$ on average. This suggests that the improvements made in the QA4ECV OMI HCHO fitting code do not lead to substantial changes in the $\mathrm{HCHO}$ columns, but we will see later that there is considerable impact on the uncertainties of the fits.

We see similar behaviour for the GOME-2A HCHO SCDs provided by the GO2AHCHO-BIRA and GO2AHCHOQA4ECV algorithms (Fig. 2b). As with OMI, averaged over all latitudes the difference between $\triangle \mathrm{SCDs}$ is small $\left(<0.9 \times 10^{15}\right.$ molec. $\left.\mathrm{cm}^{-2}\right)$. For the retrieved SCDs, the differences are larger (up to $15 \times 10^{15}$ molec. $\mathrm{cm}^{-2}$ ) at all latitudes, stressing the importance of the background correction.

\subsubsection{Evaluating slant column density uncertainties}

\section{DOAS SCD uncertainty}

The DOAS technique tries to minimise the differences between the observed and the modelled spectra within a nominal wavelength window (spectral points of length $K$ ). The Levenberg-Marquardt non-linear least-squares fitting procedure $(\mathrm{M}-\mathrm{L})$ is the numerical routine that performs the $\chi^{2}-$ merit function minimisation (Press et al., 1997) and provides the fitting parameters (of length $M$ ) (SCDs, $N_{\mathrm{s}}$ ) and a covariance matrix that contains an estimate of the uncertainty in the fitting parameters (SCD uncertainty, $\varepsilon_{N_{\mathrm{s}, j}}$; "DOAS SCD uncertainty" hereafter) for a typical non-linear fit. This routine is also used by a mostly linear fit in order to find the non-linear parameters, followed by a solution (the QR decomposition of the cross sections matrix for QDOAS and the singular value decomposition for NLIN) for a typical least squares problem for the linear parameters.

The diagonal elements of the covariance matrix, $\mathbf{C}$, are the variances of the fitted parameters. The uncertainty in the fitted parameter, $\varepsilon_{N_{\mathrm{s}, j}}$, is the square root of the variance:

$\varepsilon_{N_{\mathrm{s}, j}}=\sqrt{\chi^{2}\left(\mathbf{A}^{T} \mathbf{A}\right)_{j j}^{-1}}$,

where $\mathbf{A}$ is the matrix formed by the absorption cross sections, which has $K \times M$ components constructed from the $M$ basis functions evaluated at the $K$ abscissas $x_{i}$ (i.e. $X_{1}(x)$, $\left.\ldots, X_{M}(x)\right)$, and from the $K$ measurement errors $\varepsilon_{i}$, using the prescription

$$
\mathbf{A}_{i j}=\frac{X_{j}\left(x_{i}\right)}{\varepsilon_{i}} .
$$

The off-diagonal elements are the covariances between the parameters. In the non-linear intensity fit approach of Eq. (1) all components of the fit are accounted for in the uncertainty estimate. In the QDOAS and NLIN fits (Eq. 2) only the linear components in the fit are accounted for: uncertainties on estimated values of the non-linear parameters (i.e. shift, squeeze and intensity offset parameters) are not taken into account in the uncertainty estimate of the SCDs, and the measurement errors are not used in the fit $\left(\varepsilon_{i}=1\right)$ (Danckaert et al., 2017). The SCD uncertainties are then estimated using the reduced $\chi^{2}$ (instead of the nominal $\chi^{2}$ ), i.e. Eq. (3b) divided by the number of degrees of freedom in the fit, $K-M$.

Uncertainties on the retrieved SCDs thus depend on the following: 
1. the accuracy (sensitivity) of the fitting model in capturing the ensemble of spectral features in the observed, noisy reflectance spectrum,

2. the uncertainty in the measurements,

3. wavelength calibration.

The DOAS SCD uncertainty may consist of two parts: a random and a systematic error component.

\section{A posteriori statistical SCD uncertainty}

To evaluate the DOAS SCD uncertainty estimates and to have an independent means to intercompare the results of the different retrieval methods, we apply an alternative, statistical method. We follow the approach laid out in Wenig et al. (2001) and Boersma et al. (2007) to quantify the spatial SCD variability over pristine, unpolluted areas and assume that such estimates serve as a statistical indicator of the SCD uncertainty. The main contributors to the SCD variability are the instrument (level 1) noise, natural variability within the unpolluted area, scene reflectance (surface, clouds) and viewing geometry variability. Our objective is to provide an estimate of the random component of the SCD uncertainty by limiting the contributions from other components to the variability over the unpolluted area. We focus our analysis on the remote area within $60^{\circ} \mathrm{N}-60^{\circ} \mathrm{S}$ and $150-180^{\circ} \mathrm{W}$ (Pacific Ocean). Practically free of tropospheric pollution, this area is separated in $2^{\circ} \times 2^{\circ}$ (longitude $\times$ latitude) "boxes", which limits geophysical variability and provides statistically robust sampling. We assume that pixels within each box record the same $\mathrm{NO}_{2}$ or $\mathrm{HCHO}$ total vertical columns. Any variability emerging in the retrieved (all- or clear-sky) ensemble is then attributed to random uncertainty originating from noise in the level 1 data and imperfections in the spectral fitting model, as long as the geometric AMFs within the box show little variability ${ }^{4}$. Sun glint over the ocean may cause natural SCD variability for mostly cloud-free scenes, and we investigate this further by segregating the data into two broad categories.

Boxes with relative AMF variability of more than $5 \%$ are discarded to prevent variability in viewing geometry influencing the results. In practice, the AMF variability in most boxes does not exceed $3.5 \%$; i.e. SCDs in each box are observed under very similar viewing geometries. For these boxes we compute standard deviations of the SCDs as the statistical SCD uncertainties. In the DOAS fit, $\mathrm{NO}_{2}$ is fitted assuming a fixed temperature for its absorption cross section of $T_{0}=220 \mathrm{~K}$, and $\mathrm{HCHO}$ is fitted assuming $T_{0}=298 \mathrm{~K}$. In most retrieval algorithms, a post-correction on the slant columns is applied to compensate for neglecting the actual

\footnotetext{
${ }^{4}$ The relative AMF variability for each box was computed as follows: $\left(\overline{M_{i}^{2}}-{\overline{M_{i}}}^{2}\right)^{0.5} / \overline{M_{i}}$, where $M_{i}$ is the AMF attributed to each pixel within the box.
}

atmospheric temperature of the trace gas, but this is typically done in the later AMF step. The slant columns used in this analysis are not yet corrected for the temperaturedependency of the $\mathrm{NO}_{2}$ and $\mathrm{HCHO}$ absorption cross sections. For all OMI algorithms the DOAS uncertainty estimates may contain contributions from stripes. The statistical HCHO SCD uncertainties reported in the following sections concern the differential HCHO SCDs $(\triangle \mathrm{SCDs})$, which are known to suffer to a lesser extent from this artefact (see Sects. 2.1 and 4.3).

\subsubsection{OMI $\mathrm{NO}_{2} \mathrm{SCD}$ uncertainties}

We now compare the OMI $\mathrm{NO}_{2}$ DOAS and statistical SCD uncertainty estimates. The algorithms show a slight decrease in statistical and DOAS $\mathrm{NO}_{2} \mathrm{SCD}$ uncertainties with increasing latitude (Fig. 3). For OMNO2A v1, v2, and OMINO2QA4ECV the DOAS uncertainty exceeds the statistical uncertainty. We attribute this to persistent (systematic) fitting residuals and signatures unexplained by the fitting technique. Averaged over all latitudes, the relative difference between the statistical and DOAS uncertainty reduces from $\sim 60 \%$ for OMNO2A v1 to $\sim 20 \%$ for OMINO2-QA4ECV. This reduction hints at an improved understanding of the spectral features, and especially at the reduction in systematic parts of the residuals in the OMINO2-QA4ECV spectral fitting method relative to OMNO2A v1, in line with findings in Van Geffen et al. (2015) and Anand et al. (2015) that OMNO2A $\mathrm{v} 1$ was suffering from inaccurate wavelength calibration.

Both statistical and DOAS SCD uncertainties are on average smallest for OMINO2-QA4ECV (15 and 35\% lower than OMNO2A v1), which may indicate a more physically accurate fitting model for that algorithm. The DOAS uncertainty from OMNO2-NASA shows a smoother geographical variation than the pattern of the statistical uncertainty, which shows substantial variation with latitude (Fig. 3d). The average OMNO2-NASA DOAS and statistical uncertainties are of similar magnitude, in contrast to higher DOAS than statistical uncertainties for OMNO2A v1, v2 and OMINO2QA4ECV. The OMNO2-NASA v3.1 DOAS SCD uncertainties are on average $40 \%$ lower than v3.0. This reduction in the DOAS SCD uncertainties stems from a correction of an error in the v3.0 algorithm. The statistical SCD uncertainties are similar between v3.1 and v3.0 (agreement within $0.02 \times 10^{15}$ molec. $\mathrm{cm}^{-2}$ ). The DOAS and statistical uncertainties shown in Fig. 3 for the OMNO2A versions are consistent with estimates reported for OMNO2A v1 in Boersma et al. (2007) and Anand et al. (2015), and for OMNO2A v2 in Van Geffen et al. (2015).

Figure 4 shows histograms of the absolute differences between the individual SCDs and the box-mean SCD for OMNO2A v1 and v2, OMINO2-QA4ECV, and OMNO2NASA. The histogram of SCD differences in the OMINO2QA4ECV ensemble has the highest peak and smallest width (FWHM $1.6 \times 10^{15}$ molec. $\mathrm{cm}^{-2}$ ) of the four algorithms. All 

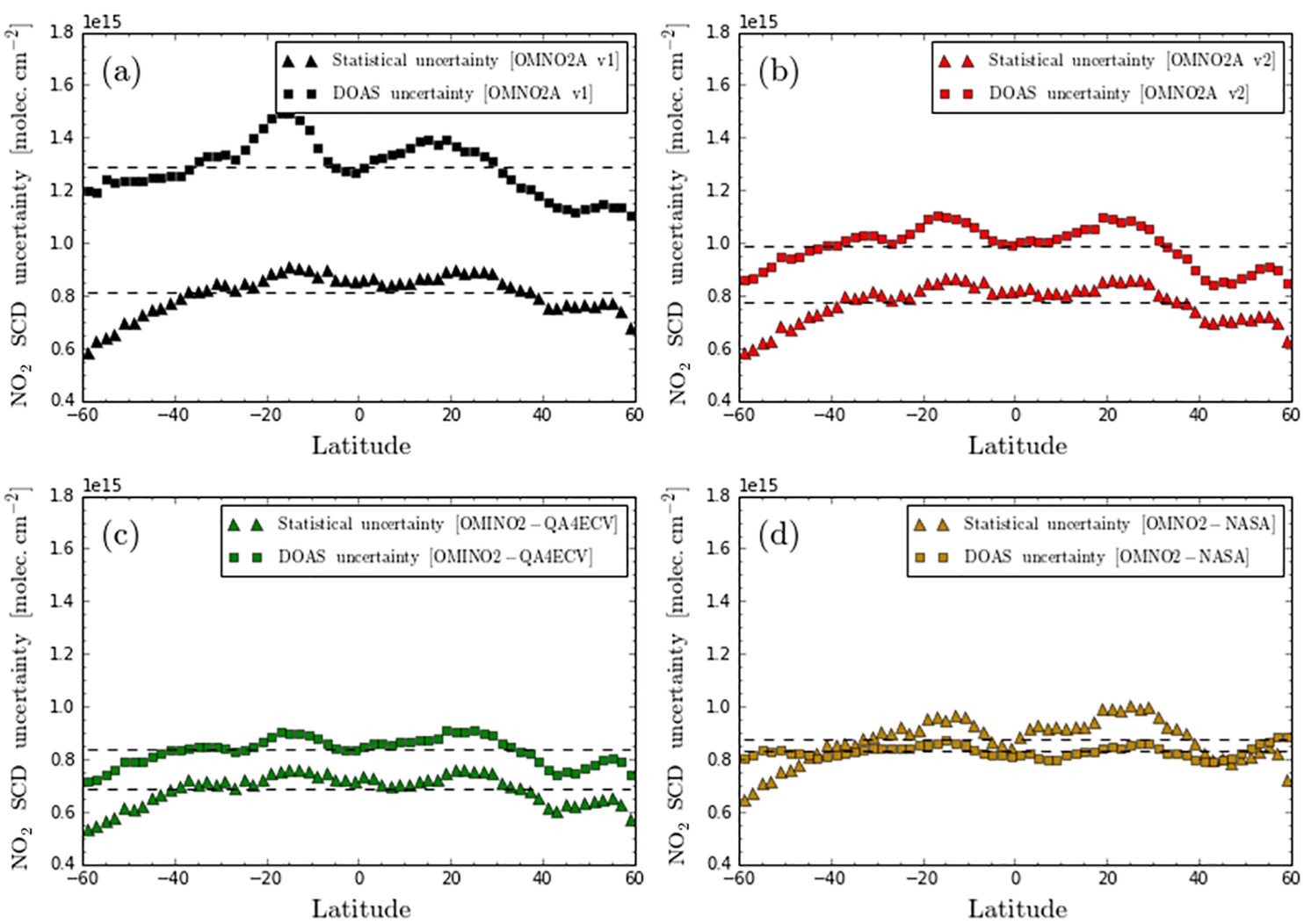

Figure 3. Average statistical (triangles) and DOAS (squares) $\mathrm{OMI} \mathrm{NO}_{2} \mathrm{SCD}$ uncertainty of all boxes within $2^{\circ}$ wide latitudinal bins for the OMNO2A v1 (a, black), OMNO2A v2 (b, red), OMINO2-QA4ECV (c, green), and OMNO2-NASA (d, yellow) slant columns for the Pacific orbit from day 1 of January, April, July, and October 2005-2015. The standard deviation of the slant columns in a box stands for the statistical uncertainty, while the box-mean value of the DOAS fit uncertainties stands for the DOAS uncertainty. We require at least 10 pixels within a box for a robust application of statistical analysis. The dashed line represents the average slant column uncertainty over all latitudes. No cloud screening has been applied.

histograms closely follow a Gaussian distribution, which is consistent with our initial assumption that random errors in the slant columns are responsible for the variability within each box, and originate mostly from measurement noise. The width $(1 \sigma)$ of the Gaussian function fitted to the observed distributions can be used as an alternative indicator of the overall, mission-averaged statistical uncertainty in the SCDs for the different algorithms. The missionaverage uncertainty for the OMINO2-QA4ECV amounts to $0.69 \times 10^{15}$ molec. $\mathrm{cm}^{-2}$, with significantly larger values for the OMNO2A and OMNO2-NASA algorithms. These findings are in agreement with the statistical uncertainty averaged over all latitudes shown as dashed lines in Fig. 3. Table 4 summarises the estimates of the statistical and DOAS uncertainties for OMNO2A v1, v2, OMINO2-QA4ECV and OMNO2-NASA SCDs for all-sky and clear-sky situations.

One question is whether SCDs for dark scenes are more uncertain than the SCDs obtained for bright scenes. The dark scenes, often associated with clear-sky conditions (cloud radiance fraction $<0.5$ ), are of most interest for tropospheric retrievals. In the studies by Anand et al. (2015) and
Marchenko et al. (2015), it was suggested that spectral fitting over (partly) cloudy scenes may result in less stable SCDs because of substantial wavelength shifts caused by the inhomogeneous illumination of the instrument slit (Voors et al., 2006). On the other hand, bright scenes have higher reflectance levels and therefore potentially higher signal-tonoise ratios, and if the wavelength calibration is sufficiently accurate in the fitting procedure, lower SCD uncertainties may be expected for such scenes. We repeated the statistical tests for the spectral fitting algorithms shown in Figs. 3 and 4, but only selected SCDs obtained under relatively cloud-free (clear-sky) conditions. For clear-sky scenes, the SCD uncertainty varies less with latitude than shown in Fig. 3 and the absolute uncertainties are higher by a factor of 1.1 compared to the all-sky SCD uncertainty estimates. This indicates that reduced signal-to-noise in the level 1 data (dark scenes) increases absolute SCD uncertainties. We recommend using the statistical estimates for clear-sky conditions in Table 4 as adequate estimates of SCD uncertainties for the above algorithms in the context of tropospheric $\mathrm{NO}_{2}$ column retrievals. 
Table 4. Statistical and DOAS uncertainty estimates of OMI $\mathrm{NO}_{2}$ SCDs for OMNO2A v1, v2, OMINO2-QA4ECV and OMNO2-NASA algorithms, and of GOME-2A NO 2 SCDs for GONO2A-BIRA and GONO2A-QA4ECV algorithms, for the Pacific orbit from day 1 of January, April, July, and October 2005-2015 for all-sky conditions (top panel) and clear-sky conditions (cloud radiance fraction < 0.5) (bottom panel). The cloud radiance fraction (crf) is the fraction of the radiation from the cloudy part of the pixel.

\begin{tabular}{|c|c|c|c|c|c|c|}
\hline $\begin{array}{l}\text { SCD uncertainty } \\
\text { (all-sky) }\end{array}$ & $\begin{array}{l}\text { OMNO2A v1 } \\
\left(\text { molec. } \mathrm{cm}^{-2}\right)\end{array}$ & $\begin{array}{r}\text { OMNO2A v2 } \\
\left(\text { molec. } \mathrm{cm}^{-2}\right)\end{array}$ & $\begin{array}{r}\text { OMINO2-QA4ECV } \\
\left(\text { molec. } \mathrm{cm}^{-2}\right)\end{array}$ & $\begin{array}{r}\text { OMNO2-NASA } \\
\left(\text { molec. } \mathrm{cm}^{-2}\right)\end{array}$ & $\begin{array}{r}\text { GONO2A-BIRA } \\
\left(\text { molec. } \mathrm{cm}^{-2}\right)\end{array}$ & $\begin{array}{r}\text { GONO2A-QA4ECV } \\
\left(\text { molec. } \mathrm{cm}^{-2}\right)\end{array}$ \\
\hline Statistical & $0.83 \times 10^{15}$ & $0.78 \times 10^{15}$ & $0.69 \times 10^{15}$ & $0.83 \times 10^{15}$ & $0.64 \times 10^{15}$ & $0.56 \times 10^{15}$ \\
\hline DOAS & $1.32 \times 10^{15}$ & $0.99 \times 10^{15}$ & $0.84 \times 10^{15}$ & $0.83 \times 10^{15}$ & $0.89 \times 10^{15}$ & $0.80 \times 10^{15}$ \\
\hline \multicolumn{7}{|c|}{ SCD uncertainty $(\operatorname{crf}<0.5)$} \\
\hline Statistical & $0.89 \times 10^{15}$ & $0.85 \times 10^{15}$ & $0.76 \times 10^{15}$ & $0.89 \times 10^{15}$ & $0.94 \times 10^{15}$ & $0.73 \times 10^{15}$ \\
\hline DOAS & $1.36 \times 10^{15}$ & $1.11 \times 10^{15}$ & $0.91 \times 10^{15}$ & $0.89 \times 10^{15}$ & $1.15 \times 10^{15}$ & $0.94 \times 10^{15}$ \\
\hline
\end{tabular}

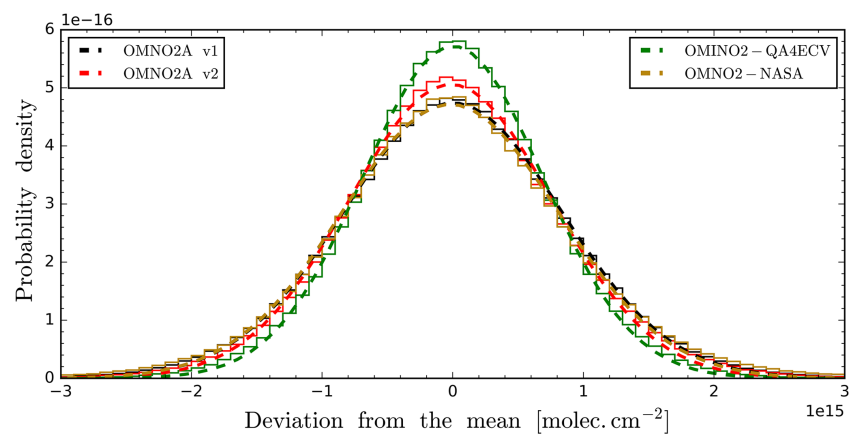

Figure 4. Distribution of the deviation of the $\mathrm{OMI} \mathrm{NO}_{2} \mathrm{SCDs}$ from the mean SCD within a box (for all boxes) in a histogram for OMNO2A v2 (red), OMINO2-QA4ECV (green), and OMNO2-NASA (yellow) algorithms against the reference OMNO2A v1 (black). The width, $\sigma$, of the Gaussian provides an estimate of the SCD uncertainty for each SCD retrieval algorithm $\left(\sigma_{\mathrm{v} 1}=0.833 \pm 0.003 \times 10^{15}\right.$ molec. $\mathrm{cm}^{-2}, \sigma_{\mathrm{v} 2}=0.776 \pm 0.005 \times$ $10^{15}$ molec. $\mathrm{cm}^{-2}, \quad \sigma_{\mathrm{qa} 4 \mathrm{ecv}}=0.688 \pm 0.003 \times 10^{15}$ molec. $\mathrm{cm}^{-2}$, $\sigma_{\text {nasa }}=0.829 \pm 0.006 \times 10^{15}$ molec. $\mathrm{cm}^{-2}$ ). The histogram contains contributions from all boxes within the reference sector for the $\mathrm{Pa}$ cific orbit from day 1 of January, April, July, and October 20052015. No cloud screening has been applied.

Boersma et al. (2007) reported that the uncertainty in the OMI $\mathrm{NO}_{2}$ retrievals due to spectral fitting with the OMNO2A v1 set-up is of the order of $0.7 \times 10^{15}$ molec. $\mathrm{cm}^{-2}$ based on the variability seen in the de-striped SCDs over the Pacific on 7 August 2006, when the row anomaly was still confined and affected only one of OMI's rows. The larger statistical uncertainty found here for the OMNO2A v1 SCDs for the 2005-2015 time period $\left(\sim 0.8 \times 10^{15}\right.$ molec. $\left.\mathrm{cm}^{-2}\right)$ is thus reasonable. The OMNO2A v2 statistical uncertainty is slightly $(\sim 6 \%)$ lower than for OMNO2A v1. Van Geffen et al. (2015) found the DOAS SCD uncertainties computed by the OMNO2A v1 and v2 spectral fits to be $1.3 \times 10^{15}$ and $1.0 \times 10^{15}$ molec. $\mathrm{cm}^{-2}$ respectively for Pacific Ocean orbits in 2007. The improvements to the OMNO2A v2 spectral fit reduced the DOAS slant column uncertainty by approx-

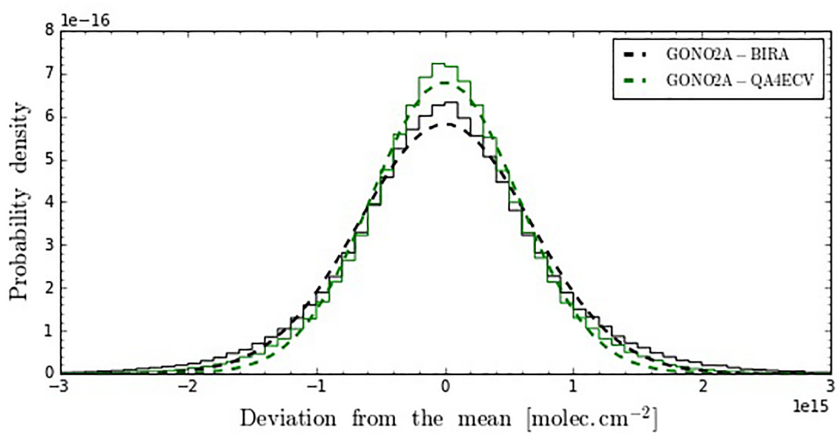

Figure 5. Distribution of the deviation of the SCDs from the mean SCD within a box (for all boxes) in a histogram for GONO2A-QA4ECV (green) algorithm against the reference GONO2A-BIRA (black). The width, $\sigma$, of the Gaussian provides an estimate of the SCD uncertainty for each SCD retrieval algorithm $\left(\sigma_{\text {bira }}=0.635 \pm 0.008 \times 10^{15}\right.$ molec. $\mathrm{cm}^{-2}, \sigma_{\mathrm{qa} 4 \mathrm{ecv}}=$ $0.556 \pm 0.006 \times 10^{15}$ molec. $\left.\mathrm{cm}^{-2}\right)$. The histogram contains contributions from all boxes within the reference sector for the Pacific orbit from day 1 of January, April, July, and October 2007-2015. No cloud screening has been applied.

imately $0.3 \times 10^{15}$ molec. $\mathrm{cm}^{-2}$ (or $24 \%$ ). The results from our 11-year period investigated are consistent with those findings (Table 4).

\subsubsection{GOME-2A $\mathrm{NO}_{2} \mathrm{SCD}$ uncertainties}

Here we compare the GONO2A-QA4ECV with GONO2ABIRA SCD uncertainties (Fig. 5 and Table 4). As with OMI, the GOME-2A NO 2 DOAS uncertainties exceed the statistical ones. Averaged over all latitudes (not shown), for GONO2A-BIRA the DOAS uncertainty exceeds the statistical uncertainty by $26 \%$, and by $35 \%$ for GONO2A-QA4ECV. The improvement in the GONO2AQA4ECV spectral fitting is demonstrated by both DOAS and statistical uncertainties being on average 10 and $13 \%$ smaller than those for the GONO2A-BIRA data set. This is confirmed by Fig. 5, which shows the highest peak and smallest width in the histogram of the SCD 

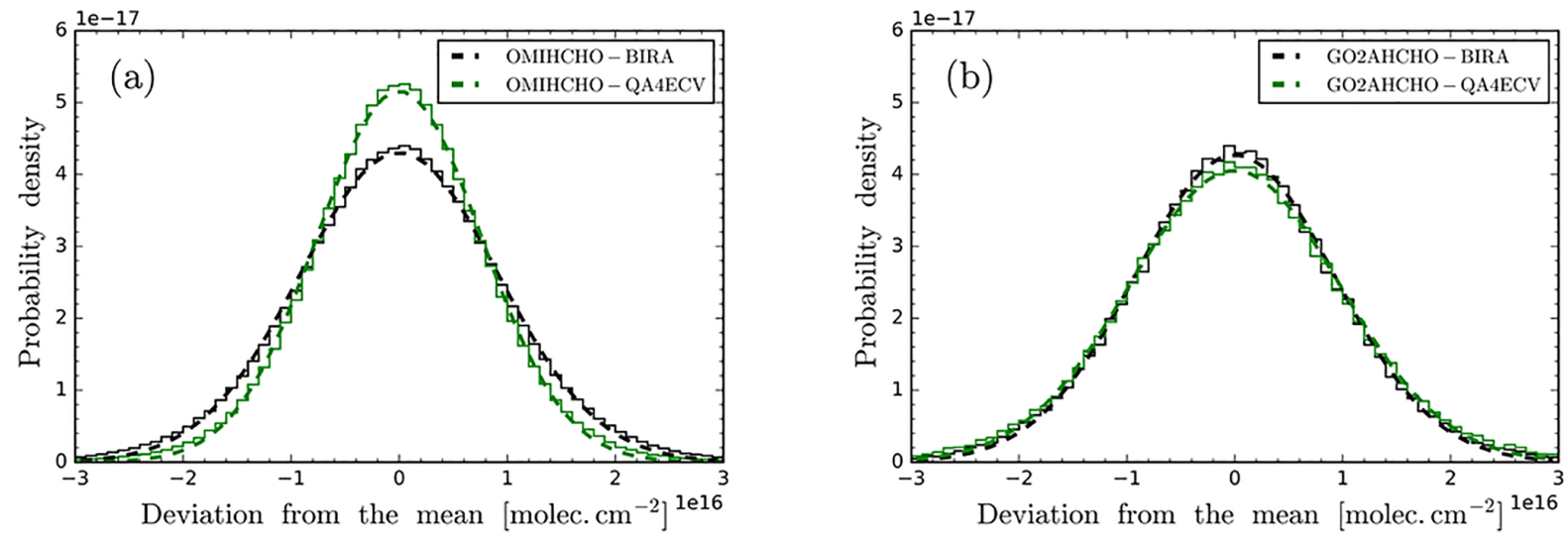

Figure 6. (a) Distribution of the deviation of the SCDs from the mean SCD within a box (for all boxes) in a histogram for OMIHCHOQA4ECV (green) against the reference OMIHCHO-BIRA (black) for the Pacific orbit from day 1 of January, April, July, and October 2005-2015. The width, $\sigma$, of the Gaussian provides an estimate of the SCD uncertainty for each SCD retrieval algorithm $\left(\sigma_{\text {bira }}=9.10 \pm\right.$ $0.04 \times 10^{15}$ molec. $\mathrm{cm}^{-2}, \sigma_{\mathrm{qa} 4 \mathrm{ecv}}=7.55 \pm 0.04 \times 10^{15}$ molec. $\mathrm{cm}^{-2}$ ). Panel (b) is as (a) but for GO2AHCHO-BIRA and GO2AHCHOQA4ECV the Pacific orbits from day 1 of January up to December and from day 15 of January, April, July, and October 2007-June 2014 and 2007-2015 respectively were used $\left(\sigma_{\text {bira }}=10.11 \pm 0.06 \times 10^{15}\right.$ molec. $\left.\mathrm{cm}^{-2}, \sigma_{\text {qa4ecv }}=11.17 \pm 0.07 \times 10^{15} \mathrm{molec}_{\mathrm{cm}} \mathrm{cm}^{-2}\right)$.

vs. box-mean SCD differences for GONO2A-QA4ECV (FWHM $1.3 \times 10^{15}$ molec. $\mathrm{cm}^{-2}$ ) compared to GONO2ABIRA (FWHM $1.5 \times 10^{15}$ molec. $\mathrm{cm}^{-2}$ ). The deviations of the SCDs from the box-mean SCD form a normal distribution illustrative of the random nature of the noise in the GOME-2A level 1 data which drives the total SCD uncertainty. We conclude that, similarly to OMI, the improved QA4ECV fitting algorithm results in more precise fitting results for $\mathrm{NO}_{2}$.

The mission-average QA4ECV $\mathrm{NO}_{2} \mathrm{SCD}$ uncertainties from OMI and GOME-2A are comparable in magnitude; the statistical and DOAS uncertainty for GOME$2 \mathrm{~A}\left(0.56 \times 10^{15}\right.$ and $0.80 \times 10^{15}$ molec. $\left.\mathrm{cm}^{-2}\right)$ are lower than for OMI $\left(0.69 \times 10^{15}\right.$ and $0.84 \times 10^{15}$ molec. $\left.\mathrm{cm}^{-2}\right)$. Initially, a higher spectral fit quality was expected for GOME-2A because of the instrument's higher signal-tonoise $(2 \times$ larger than OMI; see Table 1$)$. This is indeed the case for the early years of the instruments' mission. In 2007, the GOME- $2 \mathrm{~A} \mathrm{NO}_{2} \mathrm{SCD}$ statistical uncertainty $\left(\sim 0.45 \times 10^{15}\right.$ molec. $\mathrm{cm}^{-2}$; Fig. 11 , left $)$ was lower than for OMI $\left(\sim 0.66 \times 10^{15}\right.$ molec. $\mathrm{cm}^{-2} ;$ Fig. $\left.9 \mathrm{c}\right)$. The relatively fast degradation of the GOME-2A level 1 data has deteriorated the quality of the GOME-2A fits as diagnosed by (1) severe throughput loss (see Sect. 2.2), (2) instability of the instrument slit function due to thermal fluctuations of the GOME-2A optical bench, and (3) potential degradation of the reflectance. In contrast, OMI has shown exceptional stability, even after the occurrence and expansion of the row anomaly, and after far exceeding its designed lifespan. This explains why GOME-2A retrievals show comparable SCD uncertainties to OMI and will be discussed in detail in Sect. 4.3.

\subsubsection{OMI and GOME-2A HCHO SCD uncertainties}

The spectral fitting of $\mathrm{HCHO}$ is more challenging than for $\mathrm{NO}_{2}$ because of its relatively small differential optical depth (Table 1), lower instrument signal-to-noise in the UV and stronger interferences from other absorbing species (e.g. from $\mathrm{O}_{3}$ ). Therefore, measurement noise and the presence of other species' absorption fingerprints in the same fitting window limit the $\mathrm{HCHO}$ detection. This is reflected by the larger random (and systematic) SCD uncertainties for HCHO relative to $\mathrm{NO}_{2}$. The OMIHCHO-QA4ECV SCDs have an uncertainty of $\sim 8 \times 10^{15}$ molec. $\mathrm{cm}^{-2}$ (Fig. 6a), 10 times larger than OMINO2-QA4ECV (Table 4). As for $\mathrm{NO}_{2}$, QA4ECV results also show smaller OMI HCHO SCD uncertainties compared to the BIRA algorithm. The wider QA4ECV fitting window allows for a reduction in the SCD uncertainty even though bromine monoxide $(\mathrm{BrO})$ is now included in the fitting procedure (and not pre-fitted). On average, the OMIHCHO-QA4ECV SCD uncertainties are $18 \%$ smaller than those from OMIHCHO-BIRA, confirming the improvements in spectral fitting, consistent with the extensive tests and improvements for OMI HCHO fitting (QA4ECV Deliverable 4.2 in Muller et al., 2016).

The new GOME-2A fitting algorithm (GO2AHCHOQA4ECV) did not result in a statistically significant reduction in SCD uncertainties compared to the BIRA algorithm (Fig. $6 \mathrm{~b}$ and Table 5). On average, the HCHO statistical SCD uncertainty for GO2AHCHO-QA4ECV is $11 \%$ higher than for GO2AHCHO-BIRA. The apparent lack of improvement is discussed in Sect. 4.3.3. 
Table 5. Statistical and DOAS uncertainty estimates of OMI and GOME-2A HCHO SCDs for OMIHCHO-BIRA and OMIHCHOQA4ECV (Pacific orbit from day 1 of January, April, July, and October (or closest available data) 2005-2015), and GO2AHCHO-BIRA and GO2AHCHO-QA4ECV (Pacific orbit from day 1 of January up to December and from day 15 of January, April, July, and October (or closest available data) 2007-June 2014 and 2007-2015 respectively) for all-sky conditions (top panel) and clear-sky conditions (bottom panel). The GO2AHCHO-BIRA data are provided only for scenes with cloud fraction lower than 0.4; therefore the clear-sky conditions yield similar SCD uncertainties to the all-sky conditions. Cloud radiance fraction values are typically larger than cloud fraction values; therefore SCD uncertainties for clear-sky conditions are still slightly larger than the all-sky ones.

\begin{tabular}{|c|c|c|c|c|}
\hline $\begin{array}{l}\text { SCD uncertainty } \\
\text { (all-sky) }\end{array}$ & $\begin{array}{r}\text { OMIHCHO-BIRA } \\
\left(\text { molec. } \mathrm{cm}^{-2}\right)\end{array}$ & $\begin{array}{r}\text { OMIHCHO-QA4ECV } \\
\left(\text { molec. } \mathrm{cm}^{-2}\right)\end{array}$ & $\begin{array}{r}\text { GO2AHCHO-BIRA } \\
\left(\text { molec. } \mathrm{cm}^{-2}\right)\end{array}$ & $\begin{array}{r}\text { GO2AHCHO-QA4ECV } \\
\left(\text { molec. } \mathrm{cm}^{-2}\right)\end{array}$ \\
\hline Statistical & $9.1 \times 10^{15}$ & $7.5 \times 10^{15}$ & $10.1 \times 10^{15}$ & $11.2 \times 10^{15}$ \\
\hline DOAS & $7.8 \times 10^{15}$ & $8.0 \times 10^{15}$ & $9.2 \times 10^{15}$ & $12.2 \times 10^{15}$ \\
\hline \multicolumn{5}{|c|}{ SCD uncertainty $(\operatorname{crf}<0.5)$} \\
\hline Statistical & $9.3 \times 10^{15}$ & $7.8 \times 10^{15}$ & $10.2 \times 10^{15}$ & $11.9 \times 10^{15}$ \\
\hline DOAS & $8.2 \times 10^{15}$ & $8.5 \times 10^{15}$ & $9.6 \times 10^{15}$ & $13.0 \times 10^{15}$ \\
\hline
\end{tabular}

\section{2 $\mathrm{OMI} \mathrm{NO}_{2} \mathrm{SCD}$ uncertainty dependencies}

The variability of the SCD uncertainty with latitude and the differences between the all-sky and clear-sky SCD uncertainty estimates prompt an investigation into dependencies of SCD uncertainty on potential drivers. The SCD uncertainty appears low for high latitudes, which could be caused by higher cloud fractions, SCDs, AMFs, reflectance levels, or a combination thereof at those latitudes. We binned the $\mathrm{NO}_{2}$ statistical SCD uncertainties as a function of cloud fraction, $\mathrm{SCD}$, AMF, and top-of-atmosphere reflectance (at $435 \mathrm{~nm}$ ) for OMNO2A v1, v2, OMINO2-QA4ECV, and OMNO2NASA. Figure 7 shows that $\mathrm{NO}_{2} \mathrm{SCD}$ uncertainties from all algorithms decrease systematically with increasing cloud fraction, and especially, with top-of-atmosphere reflectance, less with SCD, and not at all with AMF. The decrease in SCD uncertainty with cloud fraction is consistent with the lower SCD uncertainties for all-sky scenes listed in Table 4 . The overall SCD uncertainties range from $0.5 \times 10^{15}$ to $1.0 \times 10^{15}$ molec. $\mathrm{cm}^{-2}$, i.e. by a factor of 2 . This suggests a more precise SCD determination when clouds are present. This holds for $\mathrm{NO}_{2}$ DOAS SCD uncertainties for OMNO2A v1, v2, and QA4ECV (see Fig. S2 in the Supplement). NASA $\mathrm{NO}_{2}$ DOAS uncertainties appear invariable with cloud fraction and top-of-atmosphere reflectance but increase with SCD.

The statistical $\mathrm{NO}_{2} \mathrm{SCD}$ uncertainties generally decrease with increasing SCD (Fig. 7a). To investigate whether this is driven by the SCD itself (more signal) or by the top-ofatmosphere reflectance levels (better signal-to-noise), we use a three-step disentanglement scheme (Fig. S1 and Table S1 in the Supplement), which allows us to analyse whether SCD uncertainties for low- and high-reflectance scenes are significantly different when AMFs and SCDs are very similar. We find that for both OMINO2-QA4ECV and OMNO2NASA, the $\mathrm{NO}_{2} \mathrm{SCD}$ uncertainties are substantially higher for low-reflectance than for high-reflectance scenes. Over bright scenes, the OMINO2-QA4ECV SCD uncertainty is $35 \%$ lower than over dark scenes. This suggests that the top-of-atmosphere reflectance level is driving SCD uncertainties. We repeated the procedure to investigate whether SCD uncertainties for low and high SCD values are significantly different for pixels with very similar AMFs and topof-atmosphere reflectance levels. We find that for OMINO2QA4ECV the $\mathrm{NO}_{2}$ SCD uncertainties for both low and high SCD values are similar, suggesting that the SCD uncertainty does not depend on the SCD value. The OMNO2A v2 algorithm (not shown) yields similar results to OMINO2QA4ECV for both schemes. This supports the hypothesis that signal-to-noise (high for high reflectances) rather than signal (SCD) strength drives SCD uncertainties.

This is also evident in Fig. 8 where regions with high cloud fractions (such as $50-60^{\circ} \mathrm{S}$ ) show low $\mathrm{NO}_{2}$ (DOAS) SCD uncertainties. The OMINO2-QA4ECV SCD uncertainty (Fig. 8b) is lower over scenes with higher cloud fraction (Fig. 8c) (or with higher top-of-atmosphere reflectance; see Fig. S3). The bright(er) cloud surface enhances the intensity of the photons reaching the sensor (higher signal-tonoise), reducing the uncertainty in the SCD retrieval.

We see a general and significant improvement in the OMINO2-QA4ECV DOAS SCD uncertainties relative to OMNO2A v1 (Fig. 8a) on a global scale. Extreme SCD uncertainties at the edges of the swath are prominent in OMNO2A v1 but much reduced in OMINO2-QA4ECV. In OMNO2A v1 a fixed slit function for all 60 rows is used, whereas OMINO2-QA4ECV assigns a slit function for each across-track position individually. This improves spectral fitting for OMINO2-QA4ECV even for scenes under high viewing or solar zenith angles and bodes well for the use of the improved OMINO2-QA4ECV SCDs in the new OMI QA4ECV NO 2 ECV data product (www.qa4ecv.eu/ecvs). 

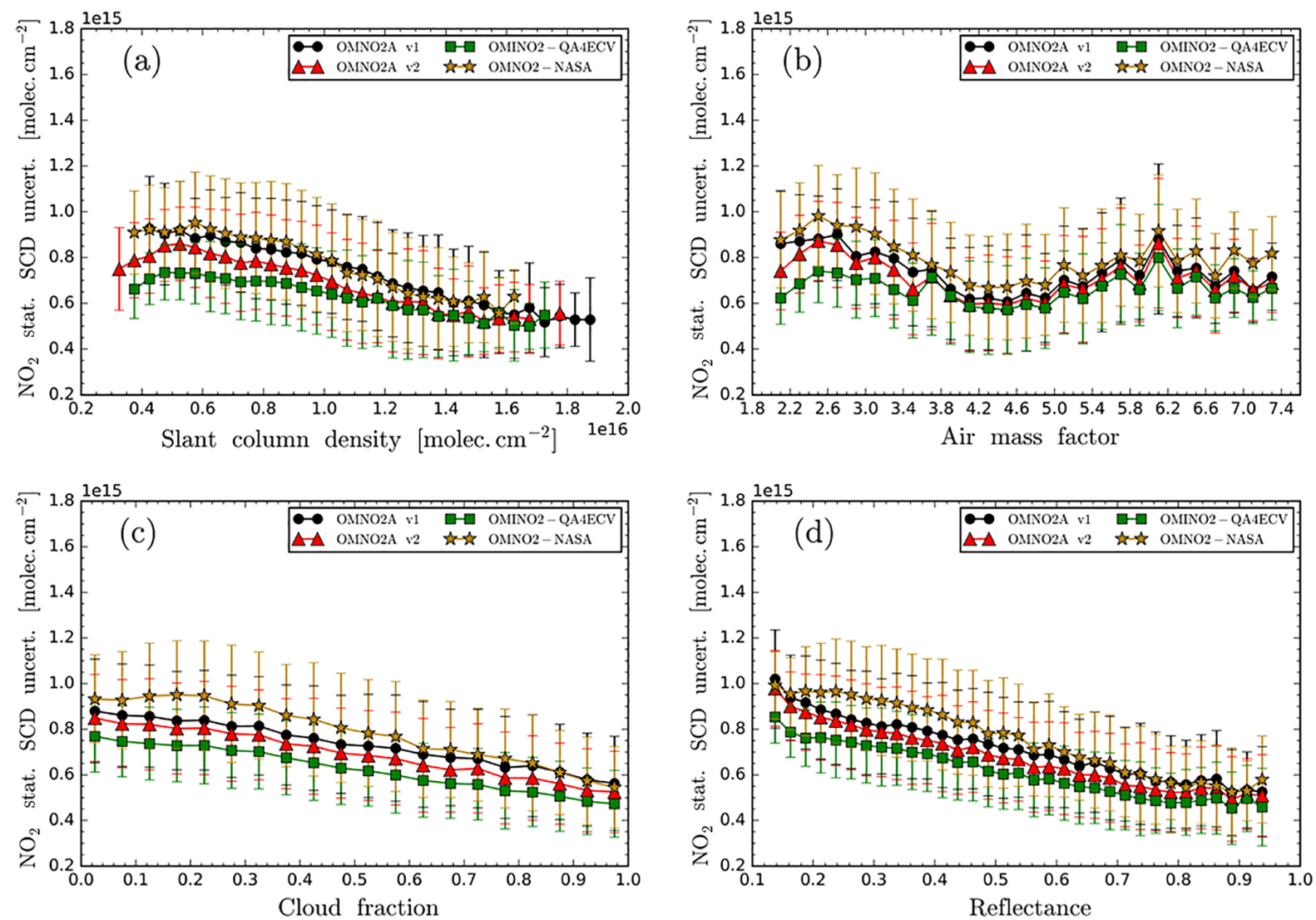

Figure 7. The statistical $\mathrm{OMI} \mathrm{NO}_{2} \mathrm{SCD}$ uncertainty as a function of the (a) SCD, (b) AMF, (c) cloud fraction, and (d) the top-of-atmosphere reflectance for the OMNO2A v1 (black circles), OMNO2A v2 (red triangles), OMINO2-QA4ECV (green squares), and the OMNO2-NASA (yellow stars) SCDs for the Pacific orbit from day 1 of January, April, July, and October (or closest available data) 2005-2015. Each bin contains at least 10 boxes for robust statistics and intercomparisons. Error bars represent 1 standard deviation $(1 \sigma)$.

\subsection{Temporal evolution of SCD uncertainties}

\subsubsection{Trends in $\mathrm{OMI} \mathrm{NO}_{2} \mathrm{SCD}$ uncertainties}

In 2017 OMI has exceeded its anticipated lifespan by 7 years. Throughout the mission, the row anomaly, stripes and the instrument's radiometric degradation all affected the SCDs and their uncertainties. In this section we discuss possible changes in stability and quality of the DOAS fits throughout the 2005-2015 period. The optical degradation in the OMI visible channel is well below $5 \%$ over the mission so far (e.g. Boersma et al., 2011; QA4ECV Deliverable 4.2 in Muller et al., 2016; Schenkeveld et al., 2017). There are, however, clear signs of gradually increasing noise in the OMI radiances and irradiances mostly related to the long-term CCD performance (Schenkeveld et al., 2017), so we should anticipate a decrease in fitting quality over time. Figure 9 shows the evolution of the statistical and DOAS NO $\mathrm{N}_{2} \mathrm{SCD}$ uncertainties for the OMNO2A v1, OMNO2A v2, OMINO2-QA4ECV and OMNO2-NASA algorithms. For all retrievals, SCD uncertainties show a weak positive trend (also see Table 6). The statistical SCD uncertainties for OMINO2-QA4ECV in- crease by $0.9 \%$ year $^{-1}$ relative to the start and well below the $\sim 2 \%$ year $^{-1}$ increase for the OMNO2A and OMNO2NASA algorithms. The OMNO2-NASA DOAS uncertainties are virtually without trend $\left(-0.3 \%\right.$ year $\left.^{-1}\right)$ in contrast with the statistical estimates. For clear-sky scenes, the rate of increase in the DOAS and statistical SCD uncertainties is somewhat higher relative to all-sky scenes for OMNO2A v1, v2 and OMINO2-QA4ECV (Table 6).

OMI shows low optical degradation and high wavelength stability over the mission lifetime. One can thus raise the question of why the SCD uncertainty increases in time, since OMI, apart from the RA, continues to perform well (Schenkeveld et al., 2017). Increases in dark current are monitored and corrected for daily, so these are unlikely to contribute to the trend. Increases in the random telegraph signal cannot be corrected for (Nico Rozemeijer, personal communication, 2017) and may contribute to a trend in SCD uncertainties. The number of pixels flagged as bad (those with offnominal behaviour) increased to $11 \%$. Furthermore, stripes are apparent in trace-gas column retrievals since the begin- 
Table 6. Yearly increase of the statistical and DOAS uncertainty estimates of OMI $\mathrm{NO}_{2}$ SCDs for OMNO2A v1, v2, OMINO2-QA4ECV, and OMNO2-NASA algorithms for the Pacific orbit from day 1 of January, April, July, and October (or closest available data) 2005-2015 for all-sky conditions (top panel) and clear-sky conditions (bottom panel).

\begin{tabular}{lrrrr}
\hline $\begin{array}{l}\text { SCD uncertainty } \\
\text { (all-sky) }\end{array}$ & $\begin{array}{r}\text { OMNO2A v1 } \\
\left(\text { year }^{-1}\right)\end{array}$ & $\begin{array}{r}\text { OMNO2A v2 } \\
\left(\text { year }^{-1}\right)\end{array}$ & $\begin{array}{r}\text { OMINO2-QA4ECV } \\
\left(\text { year }^{-1}\right)\end{array}$ & $\begin{array}{r}\text { OMNO2-NASA } \\
\left(\text { year }^{-1}\right)\end{array}$ \\
\hline Statistical & $2.9 \%$ & $2.0 \%$ & $0.9 \%$ & $1.7 \%$ \\
DOAS & $1.1 \%$ & $2.0 \%$ & $1.6 \%$ & $-0.3 \%$ \\
\hline SCD uncertainty $(\mathrm{crf}<0.5)$ & & & & \\
\hline Statistical & $3.2 \%$ & $2.3 \%$ & $1.0 \%$ & $1.3 \%$ \\
DOAS & $1.3 \%$ & $2.2 \%$ & $1.9 \%$ & $-0.1 \%$ \\
\hline
\end{tabular}
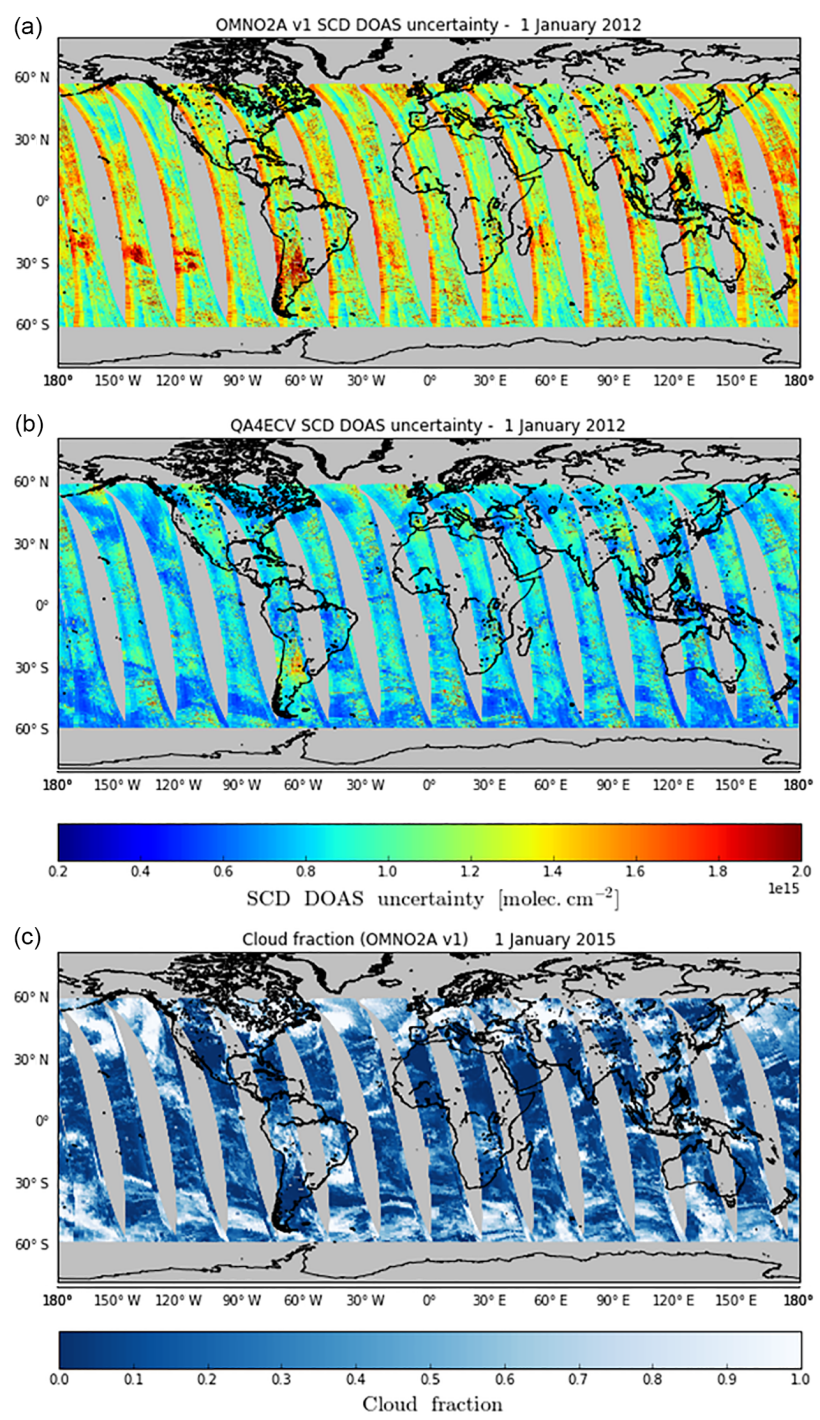

Figure 8. $\mathrm{NO}_{2}$ DOAS SCD uncertainty from the OMNO2A v1 (a) and OMINO2-QA4ECV (b) algorithms on 1 January 2012. Panel (c) shows the cloud fractions from the OMCLDO2 retrieval for the same day. ning of the mission, and their magnitude has increased over time (Boersma et al., 2011).

In Sect. 4.1.3 we saw that the $\mathrm{NO}_{2}$ DOAS SCD uncertainty generally exceeds the statistical uncertainty reflecting persistent systematic uncertainty in the DOAS fit. Here, we investigate the amount of uncertainty in the total $\mathrm{NO}_{2} \mathrm{SCD}$ uncertainty originating from stripes. This stripe-induced uncertainty is estimated as the root mean square of the stripe correction for rows 0-21 and 54-59 per OMINO2-QA4ECV orbit. Figure 10a shows the stripe-induced uncertainty increase from $0.33 \times 10^{15}$ to $0.48 \times 10^{15}$ molec. $\mathrm{cm}^{-2}$ over 2005 2015 (a $45 \%$ increase). Hence, we subtract ${ }^{5}$ (Fig. 10b) the contribution from stripes from the total $\mathrm{NO}_{2} \mathrm{SCD}$ (DOAS) uncertainty.

Total $\mathrm{NO}_{2}$ SCD (DOAS) uncertainties for OMINO2QA4ECV increase by $17.5 \%$ over 11 years. After subtracting the contribution from stripes, the SCD uncertainties increase by $9.8 \%$ over the same time period, closer to what is expected from the radiometric degradation. Accounting for stripes reduces the systematic component to the total uncertainty by $\sim 70 \%$, and the DOAS and statistical uncertainty estimates are now in better agreement (within 6\%, Fig. 10b). The statistical and DOAS uncertainty now follow the same increase rate $\left(0.9 \%\right.$ year $\left.^{-1}\right)$, suggesting that stripes explain much of the discrepancy between the DOAS and statistical uncertainty estimates (Fig. 3c). The origin of the stripes is not well known but it is most likely associated with noise and instrument-related artefacts in the solar irradiance spectrum. The presence of stripes manifests when a fixed solar spectrum (2005 annual mean for OMNO2A and OMINO2QA4ECV) is used as a reference for all years, so that the representativeness of that spectrum is reduced in years later than 2005. This is supported by the use of a daily Earth radiance spectrum as a reference rather than a fixed irradiance spectrum in OMIHCHO-QA4ECV, resulting in much weaker increases in the OMI HCHO SCD uncertainty $\left(0.3 \%\right.$ year $\left.^{-1}\right)$.

\footnotetext{
${ }^{5}$ The stripe-induced uncertainty, $\varepsilon_{\text {str }}$, is subtracted from the total SCD uncertainty (i.e. DOAS uncertainty), $\varepsilon_{\text {tot }}$, by the prescription: $\sqrt{\varepsilon_{\text {tot }}^{2}-\varepsilon_{\text {str }}^{2}}=\varepsilon_{\mathrm{w} / \mathrm{o}}$, where $\varepsilon_{\mathrm{w} / \mathrm{o}}$ is the SCD (DOAS) uncertainty without the contribution from stripes.
} 

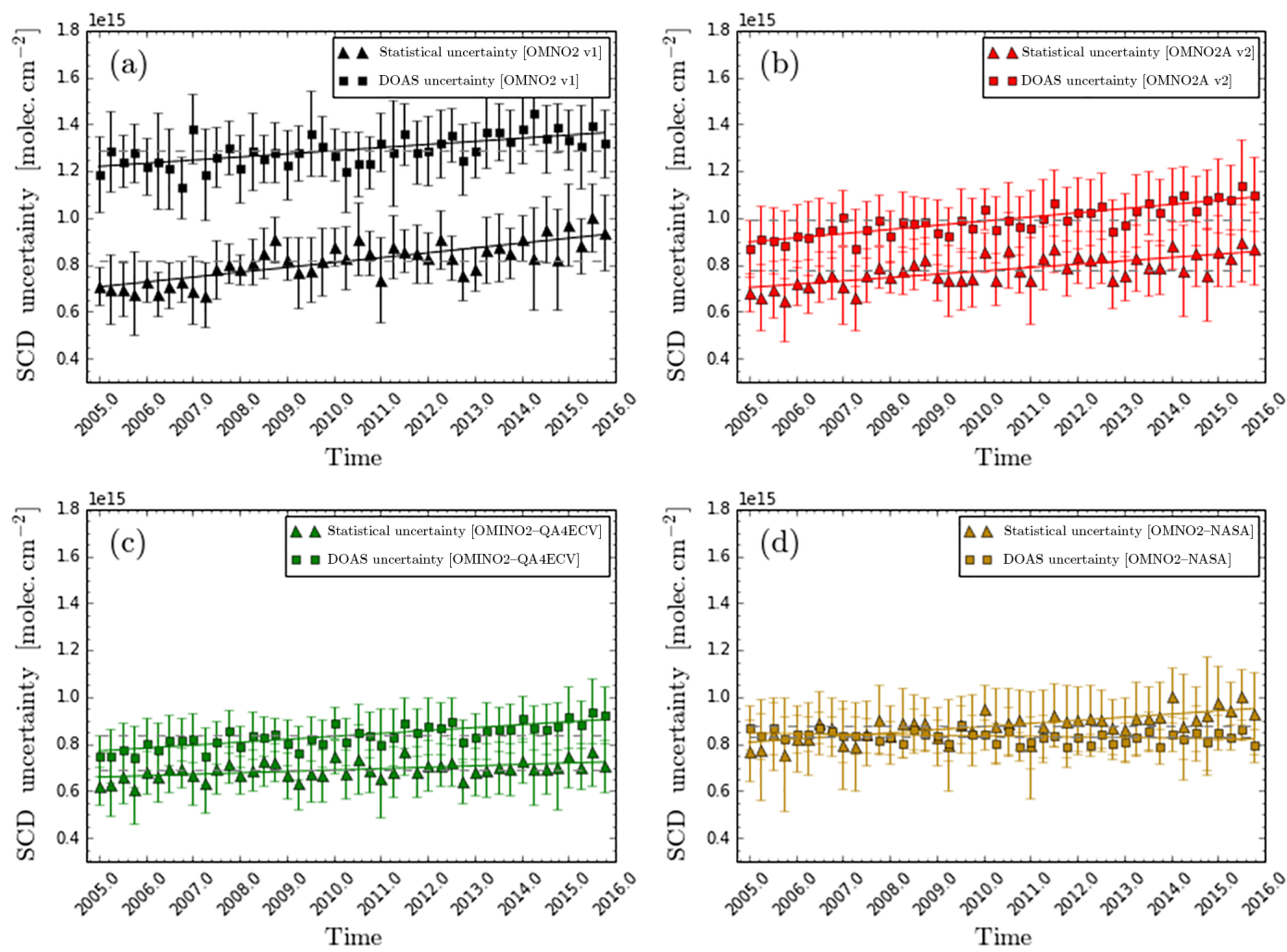

Figure 9. Temporal evolution of the statistical (triangles) and DOAS (squares) OMI $\mathrm{NO}_{2}$ SCD uncertainty over 2005-2015 (Pacific orbit from day 1 of January, April, August, October) for OMNO2A v1 (black), OMNO2A v2 (red), OMINO2-QA4ECV (green), and OMNO2NASA (yellow) algorithms. The solid line is the linear regression fitted to the data. The error bars represent 1 standard deviation $(1 \sigma)$. The slope, $p$, of each fit on the statistical, $p^{\mathrm{s}}$, and DOAS uncertainty, $p^{\mathrm{d}}$, is

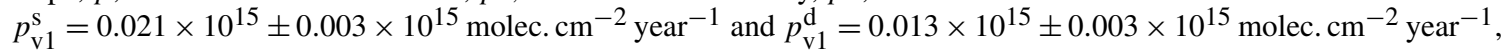

$p_{\mathrm{v} 2}^{\mathrm{s}}=0.014 \times 10^{15} \pm 0.002 \times 10^{15}$ molec. $\mathrm{cm}^{-2}$ year $^{-1}$ and $p_{\mathrm{v} 2}^{\mathrm{d}}=0.018 \times 10^{15} \pm 0.002 \times 10^{15}$ molec $^{\mathrm{cm}^{-2}}$ year $^{-1}$,

$p_{\mathrm{qa} 4 \mathrm{ecv}}^{\mathrm{s}}=0.006 \times 10^{15} \pm 0.002 \times 10^{15}$ molec. $\mathrm{cm}^{-2} \mathrm{year}^{-1}$ and $p_{\mathrm{qa} 4 \mathrm{ecv}}^{\mathrm{d}}=0.013 \times 10^{15} \pm 0.001 \times 10^{15} \mathrm{molec}^{\mathrm{cm}} \mathrm{cm}^{-2} \mathrm{year}^{-1}$, $p_{\text {nasa }}^{\mathrm{s}}=0.013 \times 10^{15} \pm 0.002 \times 10^{15}$ molec. $\mathrm{cm}^{-2}$ year $^{-1}$ and $p_{\text {nasa }}^{\mathrm{d}}=0.002 \times 10^{15} \pm 0.001 \times 10^{15} \mathrm{molec}^{\mathrm{cm}} \mathrm{cm}^{-2} \mathrm{year}^{-1}$.

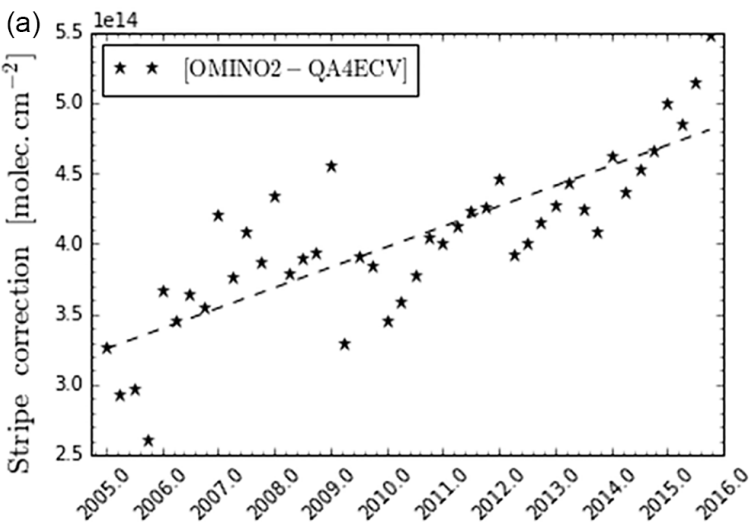

Time

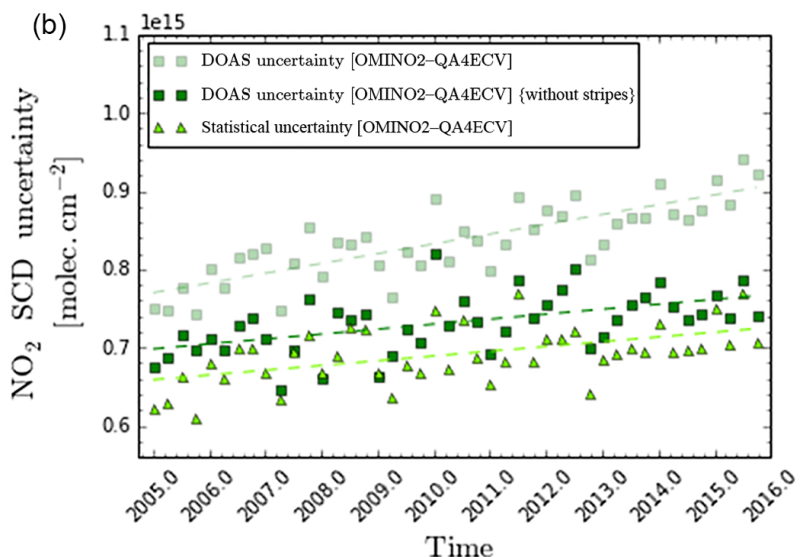

Time

Figure 10. (a) Temporal evolution of the stripe-induced SCD uncertainty for OMINO2-QA4ECV. (b) Temporal evolution of the NO 2 DOAS SCD uncertainty for OMINO2-QA4ECV before (light green squares; as seen in Fig. 9c) and after (dark-green squares) the subtraction of the stripe-induced SCD uncertainty. The green triangles represent the temporal evolution of the $\mathrm{NO}_{2}$ statistical SCD uncertainty (as seen in Fig. 9c). 

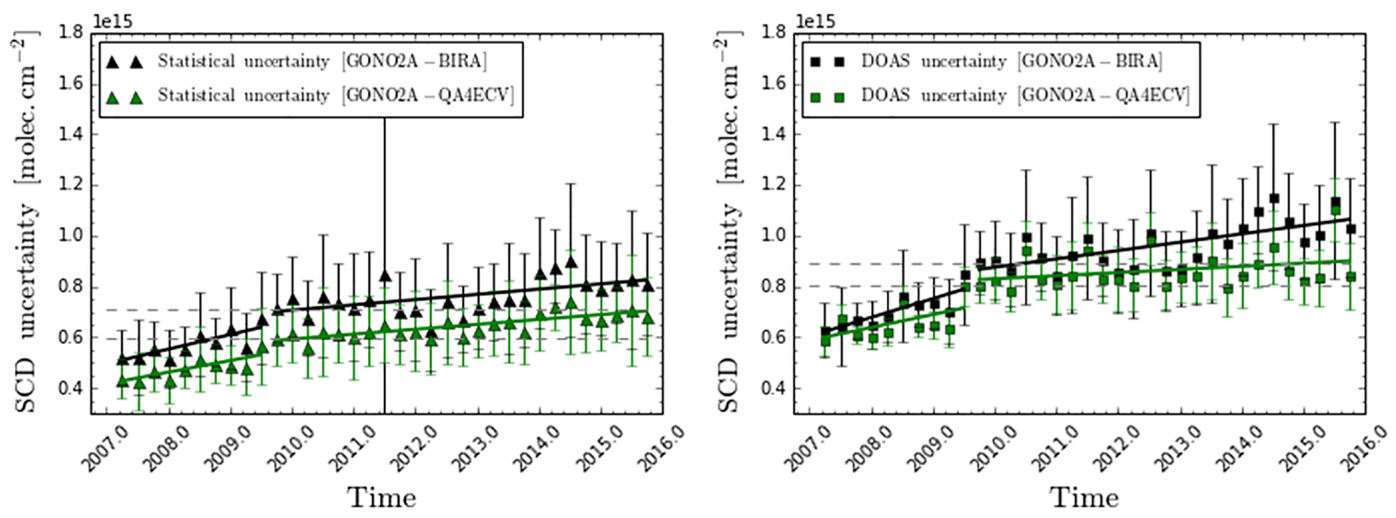

Figure 11. Temporal evolution of the statistical (triangles) and DOAS (squares) GOME-2A NO $2 \mathrm{SCD}_{2}$ uncertainty for the sub-periods before and after the second throughput test (September 2009) for GONO2A-BIRA (black) and GONO2A-QA4ECV (green) (Pacific orbit from day 1 of January, April, August, October or, closest available data, 2007-2015). Error bars represent 1 standard deviation (1 $\sigma$ ). Solid lines represent the linear regressions fitted to the data for each sub-period (Table 7). The slope, $p$, of each fit on the statistical, $p^{\mathrm{s}}$, and DOAS uncertainty, $p^{\mathrm{d}}$, before the test is

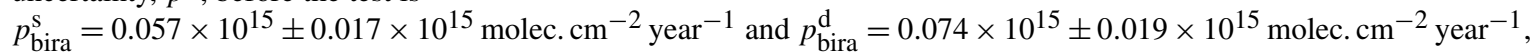

$p_{\mathrm{qa} 4 \mathrm{ecv}}^{\mathrm{s}}=0.046 \times 10^{15} \pm 0.013 \times 10^{15}$ molec. $\mathrm{cm}^{-2}$ year $^{-1}$ and $p_{\mathrm{qa} 4 \mathrm{ecv}}^{\mathrm{d}}=0.051 \times 10^{15} \pm 0.029 \times 10^{15} \mathrm{molec}^{\mathrm{cm}} \mathrm{cm}^{-2} \mathrm{year}^{-1}$.

After the test is

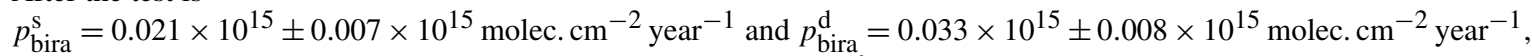

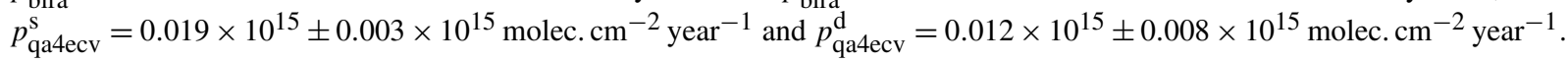

Anand et al. (2015) also pointed out these (and other) benefits from using an Earth radiance reference rather than solar irradiance spectra. For future $\mathrm{NO}_{2}$ spectral fitting algorithms the choice of radiance over irradiance spectra as a reference is debatable: on the one hand the SCDs will suffer significantly less from stripes, but on the other the retrieved SCDs will no longer be absolute rather than differential. A background correction would be required to convert differential SCDs to absolute SCDs by adding an observed climatological or modelled stratospheric slant column. As a compromise, the NASA retrieval uses monthly-averaged solar data (Marchenko et al., 2015).

\subsubsection{Trends in GOME-2A $\mathrm{NO}_{2} \mathrm{SCD}$ uncertainties}

We now investigate the performance of the BIRA and QA4ECV DOAS fits for GOME-2A throughout 2007-2015. Both GONO2A-QA4ECV DOAS and statistical uncertainties are lower than BIRA, but they still show a substantial positive trend (Fig. 11). Starting from values of $\sim 0.4$ $0.6 \times 10^{15}$ molec. $\mathrm{cm}^{-2}$ in 2007 , the GONO2A-QA4ECV statistical and DOAS uncertainties increase by 57 and $45 \%$ (relative to the start) by the end of 2015. This corresponds to an annual increase rate of $\sim 7$ and $\sim 5 \%$ year $^{-1}$ for the statistical and DOAS uncertainty, respectively (Fig. S4 and Table S2), notably higher than what was found for OMI (Table 6). A continuous spectrally dependent throughput degradation (UV: $20 \%$ year $^{-1}$; VIS: $10 \%$ year $^{-1}$ ) has been observed since the GOME-2A launch in 2007. In September 2009, a second throughput test was performed (first test was in January 2009). The second test caused an additional throughput decrease of $25 \%$ in the UV and $10 \%$ in the visible. Despite the substantial throughput loss, the test also stabilised GOME-2A degradation. The reported linear degradation rate after the second throughput test in September 2009 fell to $\sim 3 \%$ year $^{-1}$ for the UV channel and $1 \%$ for the visible channel. Munro et al. (2016) and Beirle et al. (2017) also reported a general long-term drift of the instrument's slit function, a key quantity for wavelength calibration and for convolution of the cross sections to the sensor's resolution. These changes are considerably weakened after the test and the slit function appears quite stable. Motivated by the continuous degradation of GOME-2A and the second throughput test in September 2009 with the positive effects reported on the quality of the level 1 data (EUMETSAT: GOME-2 Throughput Degradation ESA Final Report, 2011), we performed linear regressions for two sub-periods: before and after the second throughput test. The reduction in fitting quality for GONO2A-BIRA and GONO2A-QA4ECV appears to proceed at a much higher pace before the second throughput test $\left(9-12 \%\right.$ year $\left.^{-1}\right)$ than after $\left(2-4 \%\right.$ year $\left.^{-1}\right)$ (Table 7$)$, consistent with the reported degradation rate for the visible channel before $\left(11 \%\right.$ year $\left.^{-1}\right)$ and after $\left(1 \%\right.$ year $\left.^{-1}\right)$ the test. The reduction in the uncertainty increase rate is even stronger for clear-sky scenes. GOME-2A HCHO SCD uncertainties show similar behaviour: before the test the uncertainty increases at a pace of $12-17 \%$ year $^{-1}\left(20 \%\right.$ year $^{-1}$ reported for the UV), while after the test the increase rate is $1-4 \%$ year $^{-1}$ ( $3 \%$ year ${ }^{-1}$ reported for the UV). 
Table 7. Yearly increase of the statistical and DOAS uncertainty estimates for the sub-periods before and after the second throughput test (September 2009) for GOME-2A NO 2 SCDs from GONO2A-BIRA and GONO2A-QA4ECV (Pacific orbit from day 1 of January, April, August, October (or closest available data) 2007-2015) for all-sky conditions (top panel) and clear-sky conditions (bottom panel).

\begin{tabular}{|c|c|c|c|c|}
\hline $\begin{array}{l}\text { SCD uncertainty } \\
\text { (all-sky) }\end{array}$ & $\begin{array}{l}\text { GONO2A-BIRA } \\
\text { (before) }\left(\text { year }^{-1} \text { ) }\right.\end{array}$ & $\begin{array}{r}\text { GONO2A-QA4ECV } \\
\text { (before) }\left(\text { year }^{-1}\right)\end{array}$ & $\begin{array}{r}\text { GONO2A-BIRA } \\
(\text { after })\left(\text { year }^{-1}\right)\end{array}$ & $\begin{array}{r}\text { GONO2A-QA4ECV } \\
\left(\text { after) }\left(\text { year }^{-1}\right)\right.\end{array}$ \\
\hline Statistical & $11.2 \%$ & $10.7 \%$ & $2.9 \%$ & $3.3 \%$ \\
\hline DOAS & $11.9 \%$ & $8.5 \%$ & $3.8 \%$ & $1.5 \%$ \\
\hline \multicolumn{5}{|c|}{ SCD uncertainty $(\operatorname{crf}<0.5)$} \\
\hline Statistical & $12.4 \%$ & $14.2 \%$ & $3.3 \%$ & $2.6 \%$ \\
\hline DOAS & $14.0 \%$ & $11.9 \%$ & $3.7 \%$ & $1.7 \%$ \\
\hline
\end{tabular}

On 15 July 2013, GOME-2A pixel sizes were reduced from $80 \times 40$ to $40 \times 40 \mathrm{~km}^{2}$. With the integration time for each detector pixel remaining the same, the SCD uncertainties between July 2013 and December 2015 have not changed relative to the period September 2009-July 2013. Table 7 summarises the trends in GOME- $2 \mathrm{~A} \mathrm{NO} \mathrm{NO}_{2} \mathrm{SCD}$ uncertainties.

\subsubsection{Trends in OMI and GOME-2A HCHO SCD uncertainties}

Figure 12 shows the evolution of the HCHO SCD uncertainties for OMIHCHO and GO2AHCHO. For OMI, the statistical uncertainty estimates show weak positive trends of 0.5 and $0.4 \%$ year $^{-1}$ for OMIHCHO-QA4ECV and OMIHCHO-BIRA, respectively, relative to the start. This confirms the remarkable stability of the OMI level 1 data and suggests that these OMI HCHO retrievals are in principle useful for the detection of trends in $\mathrm{HCHO}$ columns. The potential impact of spectral interferences of $\mathrm{O}_{3}$ and $\mathrm{BrO}$ absorption features on the HCHO fit (e.g. González et al., 2015), and conceivably on the HCHO trends, is largely mitigated by the background correction scheme. Due to the nature of this correction, only geographically localised $\mathrm{O}_{3}$ and $\mathrm{BrO}$ trends coincidental with high $\mathrm{HCHO}$ emission regions could affect the corrected HCHO columns. Such effects, if any, are unlikely to lead to pervasive, substantial biases in $\mathrm{HCHO}$ trend analyses.

The situation is quite different for GOME-2A. Overall, the statistical QA4ECV HCHO SCD uncertainties increased from $\sim 8 \times 10^{15}$ to $14 \times 10^{15}$ molec. $\mathrm{cm}^{-2}$ (20072015 ), which corresponds to $\sim 8 \%$ year $^{-1}$ relative to the start (Fig. S5 and Table S3). The effect of the throughput test in September 2009 is evident: after the test, the QA4ECV SCD uncertainties increased by only $1-2 \%$ year $^{-1}$, a clear improvement in degradation from 12 to $17 \%$ year $^{-1}(2 \times$ the rate observed in GOME-2A NO 2 ) before the test (Fig. 12 and Table 8).

Figure 12 suggests that GO2AHCHO-QA4ECV deteriorates more than GO2AHCHO-BIRA, especially after the second throughput test. This is mainly due to the fact that
GO2AHCHO-QA4ECV uses a larger fitting window, and that GOME-2A radiances contain polarisation structures in this interval. To reduce polarisation-related systematic errors, pseudo cross sections have been included in the fit, which results in somewhat increased random uncertainty (and systematic uncertainty if not perfectly mitigated by the background correction) in the HCHO SCDs. Despite the increase in the random uncertainty, the SCD uncertainty increases at a slower pace, suggesting that the GOME-2A HCHO retrievals will allow the (challenging) detection of trends in $\mathrm{HCHO}$ columns.

\subsection{Implication for stability of long-term tropospheric $\mathrm{NO}_{2}$ ECV data sets}

According to GCOS, the user requirement for stability is a requirement on the extent to which the uncertainty of a measurement remains constant over a long period (GCOS-200, 2016). GCOS-200 defines the uncertainty (of the measurement) as the parameter that characterises the dispersion of the values that could reasonably be attributed to the measured quantity. The relevant component of the uncertainty of a measurement for climate application is often the systematic error and its maximum acceptable change, usually per decade, and it is defined by the mean error over a period such as a month or year. GCOS-154 defines the error as the difference between the measurement value and true value (GCOS$154,2011)$. We cannot assess the stability of the main (tropospheric column) product here, as this would require a major validation effort to assess a possible drift of the tropospheric column bias in time. We may, however, investigate the increases in SCD uncertainties in time and evaluate to what extent changes in noise would still allow a meaningful trend analysis in tropospheric and stratospheric columns.

\section{Stratospheric $\mathrm{NO}_{2}$ columns}

The recent retrieval developments (e.g. the systematic reduction in SCDs by $\sim 1.2 \times 10^{15}$ molec. $\mathrm{cm}^{-2}$ along with a $30 \%$ reduction in fitting errors from OMNO2A v1 to v2 in Van Geffen et al., 2015) and the QA4ECV-driven improve- 

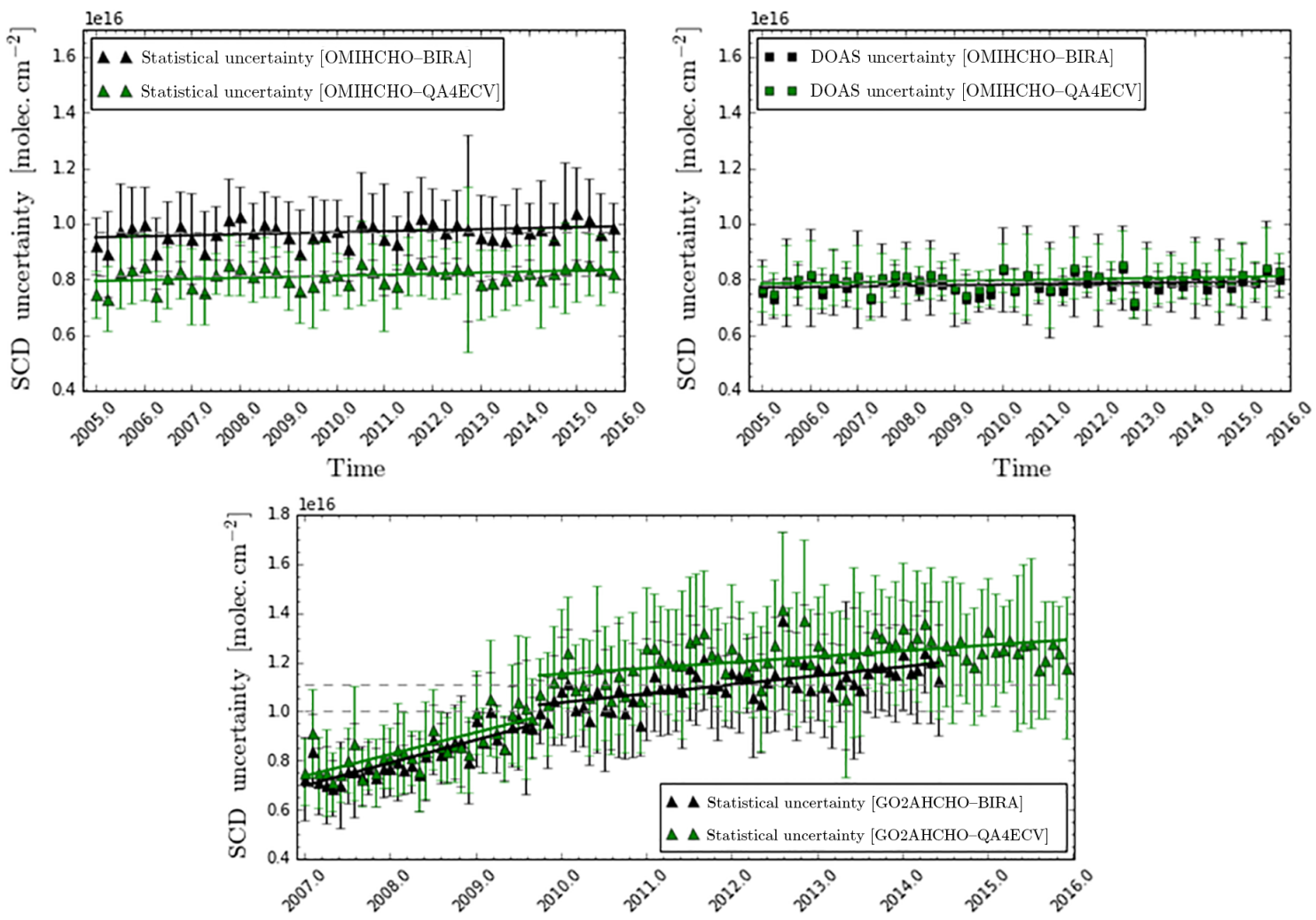

Time

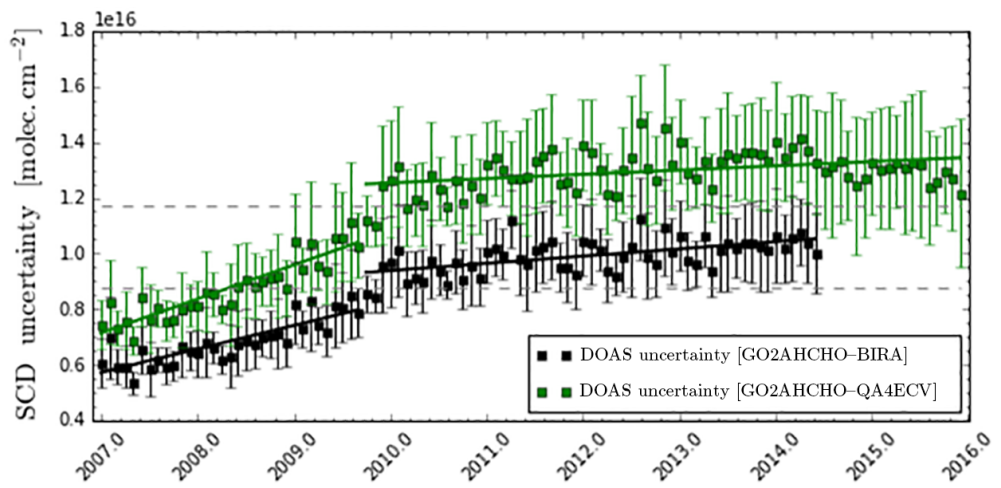

Time

Figure 12. Temporal evolution of the statistical (triangles) and DOAS (squares) OMI and GOME-2A HCHO SCD uncertainty for OMIHCHO-BIRA (black) and OMIHCHO-QA4ECV (green) (Pacific orbit from day 1 of January, April, July, and October (or closest available data) 2005-2015), and for GO2AHCHO-BIRA (black) and GO2AHCHO-QA4ECV (green) (Pacific orbit from day 1 of January up to December and from day 15 of January, April, July, and October 2007-June 2014 and 2007-2015, respectively) for the sub-periods before and after the second throughput test (September 2009). Error bars represent 1 standard deviation (1 $\sigma)$. Solid lines represent the linear regressions fitted to the data for each sub-period (Table 8). The slope, $p$, of each fit on the statistical, $p^{\mathrm{s}}$, and DOAS uncertainty, $p^{\mathrm{d}}$, for OMIHCHO is:

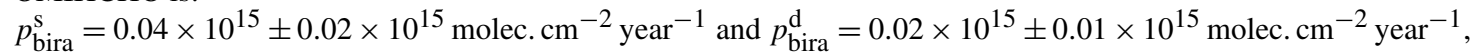

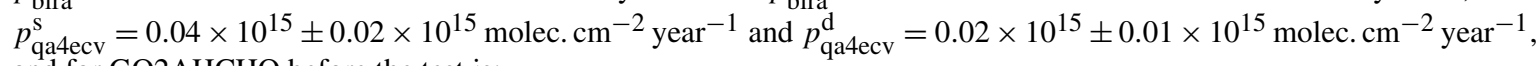
and for $\mathrm{GO} 2 \mathrm{AHCHO}$ before the test is:

$p_{\text {bira }}^{\mathrm{s}}=0.92 \times 10^{15} \pm 0.11 \times 10^{15}$ molec. $\mathrm{cm}^{-2}$ year $^{-1}$ and $p_{\text {bira }}^{\mathrm{d}}=0.84 \times 10^{15} \pm 0.10 \times 10^{15}$ molec. $^{-2}$ year $^{-1}$,

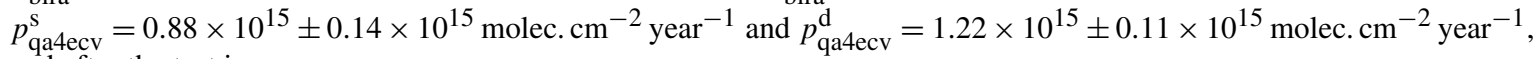
and after the test is:

$p_{\text {bira }}^{\mathrm{s}}=0.03 \times 10^{15} \pm 0.06 \times 10^{15}$ molec. $\mathrm{cm}^{-2}$ year $^{-1}$ and $p_{\text {bira }}^{\mathrm{d}}=0.26 \times 10^{15} \pm 0.05 \times 10^{15}$ molec. $\mathrm{cm}^{-2}$ year $^{-1}$,

$p_{\text {qa4ecv }}^{\mathrm{s}}=0.23 \times 10^{15} \pm 0.05 \times 10^{15}$ molec. $\mathrm{cm}^{-2}$ year $^{-1}$ and $p_{\mathrm{qa} 4 \mathrm{ecv}}^{\mathrm{d}}=0.15 \times 10^{15} \pm 0.04 \times 10^{15} \mathrm{molec}_{\mathrm{cm}}^{-2} \mathrm{year}^{-1}$. 
Table 8. Yearly increase of the statistical and DOAS uncertainty estimates of OMI and GOME-2A HCHO SCDs for OMIHCHO-BIRA and OMIHCHO-QA4ECV (Pacific orbit from day 1 of January, April, August, October (or closest available data) 2007-2015), and for GONO2A-BIRA and GONO2A-QA4ECV (Pacific orbit from day 1 of January up to December and from day 15 of January, April, July, and October 2007-June 2014 and 2007-2015, respectively) for the sub-periods before and after the second throughput test (September 2009), for all-sky conditions (top panel) and clear-sky conditions (bottom panel). The GO2AHCHO-BIRA data are provided only for scenes with cloud fraction lower than 0.4 ; therefore the clear-sky conditions yield similar SCD uncertainties to the all-sky conditions.

\begin{tabular}{|c|c|c|c|c|c|c|}
\hline $\begin{array}{l}\text { SCD uncertainty } \\
\text { (all-sky) }\end{array}$ & $\begin{array}{r}\text { OMIHCHO-BIRA } \\
\left(\text { year }^{-1}\right)\end{array}$ & $\begin{array}{r}\text { OMIHCHO-QA4ECV } \\
\left(\text { year }^{-1}\right)\end{array}$ & $\begin{array}{r}\text { GO2AHCHO-BIRA } \\
\text { (before) }\left(\text { year }^{-1} \text { ) }\right.\end{array}$ & 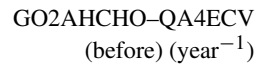 & $\begin{array}{r}\text { GO2AHCHO-BIRA } \\
(\text { after })\left(\text { year }^{-1}\right)\end{array}$ & $\begin{array}{r}\text { GO2AHCHO-QA4ECV } \\
\left(\text { after) }\left(\text { year }^{-1}\right)\right.\end{array}$ \\
\hline Statistical & $0.4 \%$ & $0.5 \%$ & $13.3 \%$ & $12.0 \%$ & $3.5 \%$ & $2.0 \%$ \\
\hline DOAS & $0.3 \%$ & $0.3 \%$ & $14.7 \%$ & $17.1 \%$ & $2.8 \%$ & $1.2 \%$ \\
\hline \multicolumn{7}{|c|}{ SCD uncertainty $(\mathrm{crf}<0.5$ ) } \\
\hline Statistical & $0.4 \%$ & $0.5 \%$ & $13.5 \%$ & $13.3 \%$ & $3.8 \%$ & $3.7 \%$ \\
\hline DOAS & $0.5 \%$ & $0.5 \%$ & $14.6 \%$ & $16.9 \%$ & $2.8 \%$ & $2.7 \%$ \\
\hline
\end{tabular}

ments reported here (Figs. 1 and 3) suggest that at least part of the SCD uncertainty is systematic rather than random but also that such systematic effects can be removed. If we consider the SCD uncertainties to be completely systematic, then we should regard the DOAS SCD uncertainties as a lower limit for trends in stratospheric $\mathrm{NO}_{2}$ that can be reliably detected from stratospheric $\mathrm{NO}_{2}$ column time series. This would imply that from, for example, the QA4ECV OMI data set, one can only infer trends in stratospheric $\mathrm{NO}_{2}$ columns larger than $0.3-0.4 \times 10^{15}$ molec. $\mathrm{cm}^{-2}$ decade $^{-1}$ (SCD uncertainty divided by typical stratospheric $\mathrm{AMF}$ ). In practice, however, the DOAS SCD uncertainty as we know it consists of a random (from level 1 noise) and a systematic (primarily from stripes) part, as shown in Sect. 4.3.1. The random component of the SCD uncertainty can be reduced to virtually zero by averaging over space and/or time. The differences between the total (i.e. DOAS) SCD uncertainty (with random + systematic contributions) and statistical SCD uncertainty (random component), as shown in Figs. 3 and 10 $\left(\varepsilon^{2}-\varepsilon_{\mathrm{r}}^{2}=\varepsilon_{\mathrm{s}}^{2}\right)$, then provide a lower limit of trend detection (from systematic uncertainty) in OMI stratospheric $\mathrm{NO}_{2}$ columns down to $0.1-0.2 \times 10^{15}$ molec. $\mathrm{cm}^{-2}$ decade $^{-1}$.

\section{Tropospheric $\mathrm{NO}_{2}$ retrievals}

Uncertainty in the SCD does not directly translate into tropospheric column uncertainty as it does for stratospheric column uncertainty. The tropospheric retrieval is based on the difference between the DOAS SCDs and estimated stratospheric SCDs, as well as various factors related to the AMF evaluation. Since the stratospheric SCDs depend on the DOAS SCDs (e.g. Dirksen et al., 2011; Beirle et al., 2016), additive systematic offsets in the SCDs will largely cancel out in the tropospheric residual SCD. In Van Geffen et al. (2015), spectral fitting retrieval improvements were shown to be mostly additive, suggesting that systematic components of the SCD uncertainty are of less relevance for $\mathrm{NO}_{2}$ tropospheric column retrievals. Marchenko et al. (2015) discussed the possibility of a considerable systematic, multiplicative factor (between OMNO2A v1 and
OMNO2-NASA), and such a component, if real, would be relevant for $\mathrm{NO}_{2}$ tropospheric column retrievals and their usefulness for trend detection. The instability in the SCDs because of stripes (OMI) or instrument degradation (GOME2A) was evaluated further by testing the robustness of the tropospheric signal over a well-chosen reference area with little known pollution. We find that for OMI and GOME$2 \mathrm{~A}$ the monthly mean tropospheric $\mathrm{NO}_{2}$ columns are stable throughout 2005 (2007 for GOME-2A)-2015 with no significant trend over a pristine region (see Fig. S6).

In the absence of a substantial systematic, multiplicative error in the $\mathrm{NO}_{2} \mathrm{SCDs}$, the stability of tropospheric $\mathrm{NO}_{2}$ vertical columns will therefore be dominated by instability in the AMF uncertainties. For instance, if assumptions on surface albedo or a priori $\mathrm{NO}_{2}$ profile shape grow increasingly inaccurate over time (because of e.g. urbanisation, increasing aerosol haze, change in vegetation), this will lead to growing systematic uncertainties in tropospheric AMFs (Lamsal et al., 2015). Such systematic or structural uncertainties may increase to up to $30-40 \%$ in rapidly changing regions such as parts of India and China (Lorente et al., 2017).

\section{Conclusions}

Recently improved spectral fitting algorithms for OMI and GOME-2A developed by BIRA-IASB, IUP, and KNMI as part of the QA4ECV consortium and also by NASA for OMI have generated new data sets of $\mathrm{NO}_{2}$ and $\mathrm{HCHO}$ slant columns that are the starting point for improved retrievals of tropospheric columns, and their quality determines the effective detection limit and usefulness for trend detection and emission estimates from the retrievals. These new data sets have not yet been quality assured, which is important in view of the known degradation of the instruments. We compared $\mathrm{NO}_{2}$ and $\mathrm{HCHO}$ slant columns retrieved from the OMI and GOME-2A instruments throughout much of their operational periods (2005-2015), and paid special attention to the characterisation of their uncertainties. 
The new QA4ECV $\mathrm{NO}_{2}$ and $\mathrm{HCHO}$ spectral fitting algorithm is an improvement over previous approaches. A wavelength calibration is applied to the full fitting window width, and the fitting equation is extended with an intensity offset term that accounts for possible effects from stray light, instrumental thermal instabilities, or dark-current changes. We find that the new QA4ECV $\mathrm{NO}_{2}$ slant columns agree very well (within $2 \%$ ) with slant column data from KNMI (OMNO2A v2) and BIRA (QDOAS) for both OMI and GOME-2A. New OMI NASA $\mathrm{NO}_{2}$ slant columns (v3.1) are also in good agreement with those from QA4ECV and KNMI. For HCHO, we find very good consistency between the QA4ECV and BIRA (differential) SCD data sets.

The improved quality of the QA4ECV OMI and GOME$2 \mathrm{~A} \mathrm{NO}_{2}$ slant columns is underlined by their low statistical uncertainties: $0.7-0.8 \times 10^{15}$ molec. $\mathrm{cm}^{-2}$ for OMI and for GOME-2A on average for clear-sky scenes. These uncertainties are lower than those from the OMNO2A v2, NASA, and BIRA algorithms $\left(\sim 0.9 \times 10^{15}\right.$ molec. $\left.\mathrm{cm}^{-2}\right)$. HCHO slant column uncertainties are also lower for OMI QA4ECV $\left(8 \times 10^{15}\right.$ down from $9 \times 10^{15}$ molec. $\left.\mathrm{cm}^{-2}\right)$, but not for GOME-2A, related to the use of a larger fitting window requiring the use of ad-hoc corrections for spectral polarisation structures. We used a statistical approach that quantifies the variability of the slant columns over pristine areas as an independent test of the DOAS uncertainties. For HCHO, we find excellent agreement between the statistical and the DOAS uncertainty estimates, suggesting that the fitting uncertainty is dominated by random noise in the satellite level 1 data for that species. This is not so for $\mathrm{NO}_{2}$, where the DOAS uncertainty estimates are systematically higher than the statistical ones, suggesting that the DOAS uncertainties for $\mathrm{NO}_{2}$ include both a random $(\sim 65 \%$ of the total uncertainty) and a systematic ( $\sim 35 \%$ of the total uncertainty) part. We found that stripes, increasing over time, can largely explain the discrepancy between statistical and DOAS uncertainties for OMI. This discrepancy diminishes in the HCHO uncertainties because of the use of radiance instead of irradiance spectra as reference in the fit.

The slant column uncertainties are driven primarily by the magnitude of the top-of-atmosphere reflectance. For relatively dark scenes corresponding to mostly cloud-free scenes and low surface albedo, $\mathrm{NO}_{2}$ uncertainties are up to $2 \times$ higher than those over bright scenes. This confirms the notion that sufficiently high signal-to-noise levels of level 1 (radiance) spectra are required for good-quality fits. Our analysis of trends in the $\mathrm{NO}_{2}$ and $\mathrm{HCHO}$ slant column uncertainties corroborates this: for the radiometrically stable OMI sensor, we find only minor increases in fitting uncertainty throughout the mission period (increases of $1-2 \%$ year ${ }^{-1}$ for $\mathrm{NO}_{2}$ ), but for GOME-2A the SCD uncertainties increase by 12 $14 \%$ year $^{-1}$ (for clear-sky scenes) up until September 2009 when a test for throughput loss was performed. After this test, which initially resulted in an additional loss of signal- to-noise, GOME-2A NO $2 \mathrm{SCD}$ uncertainties increase at a slower pace of $2-3 \%$ year $^{-1}$.

The increasing slant column uncertainties are indicative of the stability of the stratospheric and tropospheric $\left(\mathrm{NO}_{2}\right)$ column retrievals. Because the slant column uncertainty is dominated by random contributions from the propagation of measurement noise, much of it can be reduced by averaging over space and/or time, and trend detection in stratospheric $\mathrm{NO}_{2}$ down to the $\sim 1 \%$ decade $^{-1}$ level should be possible with all four OMI fitting algorithms. The stability of the longterm tropospheric $\mathrm{NO}_{2}$ record is likely limited by instability in AMF uncertainties rather than in the weak increases in SCD uncertainties reported here.

Our work points to the need for detailed validation of the new satellite data products from KNMI, NASA, and QA4ECV. Dedicated validation efforts could point out whether any systematic biases in the tropospheric columns are sufficiently constant over longer periods and could help to attribute any biases to their underlying causes in the retrieval chain.

Data availability. The QA4ECV $\mathrm{NO}_{2}$ and $\mathrm{HCHO}$ data products have been released publicly and registered (Boersma et al., 2017a, b; De Smedt et al., 2017b, c), and the data sets can be found online (www.qa4ecv.eu/ecvs, last access: 10 June 2018).

The Supplement related to this article is available online at https://doi.org/10.5194/amt-11-4033-2018-supplement.

Competing interests. The authors declare that they have no conflict of interest.

Acknowledgements. This research was funded by the FP7 EU Project Quality Assurance for Essential Climate Variables (QA4ECV), grant no. 607405.

Edited by: Ronald Cohen

Reviewed by: three anonymous referees

\section{References}

Anand, J. S., Monks, P. S., and Leigh, R. J.: An improved retrieval of tropospheric $\mathrm{NO}_{2}$ from space over polluted regions using an Earth radiance reference, Atmos. Meas. Tech., 8, 1519-1535, https://doi.org/10.5194/amt-8-1519-2015, 2015.

Bauer, S. E., Koch, D., Unger, N., Metzger, S. M., Shindell, D. T., and Streets, D. G.: Nitrate aerosols today and in 2030: a global simulation including aerosols and tropospheric ozone, Atmos. Chem. Phys., 7, 5043-5059, https://doi.org/10.5194/acp-7-50432007, 2007. 
Beirle, S., Hörmann, C., Jöckel, P., Liu, S., Penning de Vries, M., Pozzer, A., Sihler, H., Valks, P., and Wagner, T.: The STRatospheric Estimation Algorithm from Mainz (STREAM): estimating stratospheric $\mathrm{NO}_{2}$ from nadir-viewing satellites by weighted convolution, Atmos. Meas. Tech., 9, 2753-2779, https://doi.org/10.5194/amt-9-2753-2016, 2016.

Beirle, S., Lampel, J., Lerot, C., Sihler, H., and Wagner, T.: Parameterizing the instrumental spectral response function and its changes by a super-Gaussian and its derivatives, Atmos. Meas. Tech., 10, 581-598, https://doi.org/10.5194/amt-10-5812017, 2017.

Boersma, K. F., Eskes, H. J., and Brinksma, E. J.: Error analysis for tropospheric $\mathrm{NO}_{2}$ retrieval from space, J. Geophys. Res., 109, D04311, https://doi.org/10.1029/2003JD003962, 2004.

Boersma, K. F., Eskes, H. J., Veefkind, J. P., Brinksma, E. J., van der A, R. J., Sneep, M., van den Oord, G. H. J., Levelt, P. F., Stammes, P., Gleason, J. F., and Bucsela, E. J.: Near-real time retrieval of tropospheric $\mathrm{NO}_{2}$ from OMI, Atmos. Chem. Phys., 7, 2103-2118, https://doi.org/10.5194/acp-7-2103-2007, 2007.

Boersma, K. F., Eskes, H. J., Dirksen, R. J., van der A, R. J., Veefkind, J. P., Stammes, P., Huijnen, V., Kleipool, Q. L., Sneep, M., Claas, J., Leitão, J., Richter, A., Zhou, Y., and Brunner, D.: An improved tropospheric $\mathrm{NO}_{2}$ column retrieval algorithm for the Ozone Monitoring Instrument, Atmos. Meas. Tech., 4, 19051928, https://doi.org/10.5194/amt-4-1905-2011, 2011.

Boersma, K. F., Eskes, H., Richter, A., De Smedt, I., Lorente, A., Beirle, S., Van Geffen, J., Peters, E., Van Roozendael, M., and Wagner, T.: QA4ECV $\mathrm{NO}_{2}$ tropospheric and stratospheric vertical column data from OMI (Version 1.1), Data set, Royal Netherlands Meteorological Institute (KNMI), https://doi.org/10.21944/qa4ecv-no2-omi-v1.1, 2017a.

Boersma, K. F., Eskes, H., Richter, A., De Smedt, I., Lorente, A., Beirle, S., Van Geffen, J., Peters, E., Van Roozendael, M., and Wagner, T.: QA4ECV $\mathrm{NO}_{2}$ tropospheric and stratospheric vertical column data from GOME-2A (Version 1.1), Data set, Royal Netherlands Meteorological Institute (KNMI), https://doi.org/10.21944/qa4ecv-no2-gome2a-v1.1, 2017b.

Bucsela, E. J., Celarier, E., Wenig, M., Gleason, J., Veefkind, J., Boersma, K., and Brinksma, E.: Algorithm for $\mathrm{NO}_{2}$ vertical column retrieval from the ozone monitoring instrument, IEEE T. Geosci. Remote, 44, 1245-1258, https://doi.org/10.1109/TGRS.2005.863715, 2006.

Bucsela, E. J., Krotkov, N. A., Celarier, E. A., Lamsal, L. N., Swartz, W. H., Bhartia, P. K., Boersma, K. F., Veefkind, J. P., Gleason, J. F., and Pickering, K. E.: A new stratospheric and tropospheric $\mathrm{NO}_{2}$ retrieval algorithm for nadir-viewing satellite instruments: applications to OMI, Atmos. Meas. Tech., 6, 26072626, https://doi.org/10.5194/amt-6-2607-2013, 2013.

Callies, J., Corpaccioli, E., Eisinger, M., Hahne, A., and Lefebvre, A.: GOME-2 - MetOp's Second Generation Sensor for Operational Ozone Monitoring, ESA Bulletin, No. 102, 2000.

Chance, K. V. and Spurr, R. J. D.: Ring effect studies: Rayleigh scattering, including molecular parameters for rotational Raman scattering, and the Fraunhofer spectrum, Appl. Opt., 36, 52245230, https://doi.org/10.1364/AO.36.005224, 1997.

Coburn, S., Dix, B., Sinreich, R., and Volkamer, R.: The CU ground MAX-DOAS instrument: characterization of RMS noise limitations and first measurements near Pensacola, FL of
BrO, IO, and CHOCHO, Atmos. Meas. Tech., 4, 2421-2439, https://doi.org/10.5194/amt-4-2421-2011, 2011.

Danckaert, T., Fayt, C., Van Roozendael, M., De Smedt, I., Letocart, V., Merlaud, A., and Pinardi, G.: QDOAS Software user manual, Belgian Institute for Space Aeronomy (BIRA-IASB), version 3.2, available at: http://uv-vis.aeronomie.be/software/QDOAS/, 2017.

De Smedt, I., Muller, J.-F., Stavrakou, T., van der A, R., Eskes, H., and Van Roozendael, M.: Twelve years of global observations of formaldehyde in the troposphere using GOME and SCIAMACHY sensors, Atmos. Chem. Phys., 8, 4947-4963, https://doi.org/10.5194/acp-8-4947-2008, 2008.

De Smedt, I., Van Roozendael, M., Stavrakou, T., Muller, J.-F., Lerot, C., Theys, N., Valks, P., Hao, N., and van der A, R.: Improved retrieval of global tropospheric formaldehyde columns from GOME-2/MetOp-A addressing noise reduction and instrumental degradation issues, Atmos. Meas. Tech., 5, 2933-2949, https://doi.org/10.5194/amt-5-2933-2012, 2012.

De Smedt, I., Stavrakou, T., Hendrick, F., Danckaert, T., Vlemmix, T., Pinardi, G., Theys, N., Lerot, C., Gielen, C., Vigouroux, C., Hermans, C., Fayt, C., Veefkind, P., Muller, J.-F., and Van Roozendael, M.: Diurnal, seasonal and long-term variations of global formaldehyde columns inferred from combined OMI and GOME-2 observations, Atmos. Chem. Phys., 15, 12519-12545, https://doi.org/10.5194/acp-15-12519-2015, 2015.

De Smedt, I., Richter, A., Beirle, B., Danckaert, T., Van Roozendael, M., Vlietinck, J., Yu, H., Boesch, T., Hillboll, A., Peters, E., Wagner, T., Wang, Y., Lorente, A., Eskes, H., Van Geffen, J., Zara, M., and Boersma, F.: Tropospheric HCHO retrieved from OMI, GOME (-2), and SCIAMACHY within the Quality Assurance For Essential Climate Variables (QA4ECV) project, EGU General Assembly Conference Abstracts, 2017a.

De Smedt, I., Yu, H., Richter, A., Beirle, S., Eskes, H., Boersma, K.F., Van Roozendael, M., Van Geffen, J., Lorente, A., and Peters, E.: QA4ECV HCHO tropospheric column data from OMI (Version 1.1), Data set, Royal Belgian Institute for Space Aeronomy, https://doi.org/10.18758/71021031, $2017 \mathrm{~b}$.

De Smedt, I., Yu, H., Richter, A., Beirle, S., Eskes, H., Boersma, K. F., Van Roozendael, M., Van Geffen, J., Lorente, A., and Peters, E.: QA4ECV HCHO tropospheric column data from GOME-2 (Version 1.1), Data set, Royal Belgian Institute for Space Astronomy, https://doi.org/10.18758/71021032, 2017c.

De Smedt, I., Theys, N., Yu, H., Danckaert, T., Lerot, C., Compernolle, S., Van Roozendael, M., Richter, A., Hilboll, A., Peters, E., Pedergnana, M., Loyola, D., Beirle, S., Wagner, T., Eskes, H., van Geffen, J., Boersma, K. F., and Veefkind, P.: Algorithm theoretical baseline for formaldehyde retrievals from S5P TROPOMI and from the QA4ECV project, Atmos. Meas. Tech., 11, 23952426, https://doi.org/10.5194/amt-11-2395-2018, 2018.

Dikty, S. and Richter, A.: GOME-2 on MetOp-A Support for Analysis of GOME-2 In-Orbit Degradation and Impacts on Level 2 Data Products, ITT 09/10000262, Final Report, Version 2.0, 2011.

Dirksen, R., Dobber, M., Voors, R., and Levelt, P.: Prelaunch characterization of the Ozone Monitoring Instrument transfer function in the spectral domain, Appl. Opt., 45, 3972-3981, https://doi.org/10.1364/AO.45.003972, 2006.

Dirksen, R. J., Boersma, K. F., Eskes, H. J., Ionov, D. V., Bucsela, E. J., Levelt, P. F., and Kelder, H. M.: Evaluation of strato- 
spheric $\mathrm{NO}_{2}$ retrieved from the Ozone Monitoring Instrument: Intercomparison, diurnal cycle, and trending, J. Geophys. Res., 116, D08305, https://doi.org/10.1029/2010JD014943, 2011.

Dobber, M. R., Dirksen, R. J., Levelt, P. F., van den Oord, G. H. J., Voors, R. H. M., Kleipool, Q., Jaross, G., Kowalewski, M., Hilsenrath, E., Leppelmeier, G. W., de Vries, J., Dierrsen, W., and Rozemeijer, N. C.: Ozone Monitoring Instrument calibration, IEEE T. Geosci. Remote, 44, 1209-1238, https://doi.org/10.1109/TGRS.2006.869987, 2006.

Dobber, M., Kleipool, Q., Dirksen, R., Levelt, P., Jaross, G., Taylor, S., Kelly, T., and Flynn, L.: Validation of ozone monitoring instrument level-1b data products, J. Geophys. Res., 113, D15S06, https://doi.org/10.1029/2007JD008665, 2008.

Dufour, G., Szopa, S., Barkley, M. P., Boone, C. D., Perrin, A., Palmer, P. I., and Bernath, P. F.: Global uppertropospheric formaldehyde: seasonal cycles observed by the ACE-FTS satellite instrument, Atmos. Chem. Phys., 9, 38933910, https://doi.org/10.5194/acp-9-3893-2009, 2009.

EUMETSAT: GOME-2 Throughput Degradation ESA Final Report , MO.TN.ESA.GO.0985, Version 1, ESTEC, Noordwijk, the Netherlands, available at: https://www.eumetsat.int/ website $/ \mathrm{wcm} / \mathrm{idc} / \mathrm{idcp}$ lg?IdcService=GET_FILE\&dDocName $=$ PDF_GOME_THRU_DEG_ESA\&RevisionSelectionMethod= LatestReleased\&Rendition=Web (last access: 27 June 2018), 2011

Fischer, P. H., Marra, M., Ameling, C. B., Hoek, G., Beelen, R., de Hoogh, K., Breugelmans, O., Kruize, H., Janssen, N. A. H., and Houthuijs, D.: Air pollution and mortality in seven million adults: The Dutch Environmental Longitudinal Study (DUELS), Environ. Health Persp., 123, 697-704, 2015.

GCOS-138: Implementation plan for the Global Observing System for Climate in Support of the UNFCCC (2010 Update), GOOS184, GTOS-76, WMO-TD/No. 1523, WMO, 2010.

GCOS-154: Systematic Observation Requirements for Satellitebased Products for Climate Supplemental details to the satellitebased component of the Implementation Plan for the Global Observing System for Climate in Support of the UNFCCC (2011 Update), WMO, 2011

GCOS-200: The Global Observing System for Climate: Implementation Needs, (GOOS-214), WMO, 2016.

González Abad, G., Liu, X., Chance, K., Wang, H., Kurosu, T. P., and Suleiman, R.: Updated Smithsonian Astrophysical Observatory Ozone Monitoring Instrument (SAO OMI) formaldehyde retrieval, Atmos. Meas. Tech., 8, 19-32, https://doi.org/10.5194/amt-8-19-2015, 2015.

Grainger, J. F. and Ring, J.: Anomalous Fraunhofer line profiles, Nature, 193, p. 762, https://doi.org/10.1038/193762a0, 1962.

IPCC: Climate Change 2013: The Physical Science Basis, Contribution of Working Group I to the Fifth Assessment Report of the Intergovernmental Panel on Climate Change, edited by: Stocker, T. F., Qin, D., Plattner, G.-K., Tignor, M., Allen, S. K., Boschung, J., Nauels, A., Xia, Y., Bex, V., and Midgley, P. M., Cambridge, UK, New York, NY, USA, 1535 pp., https://doi.org/10.1017/CBO9781107415324, 2013.

Joiner, J., Guanter, L., Lindstrot, R., Voigt, M., Vasilkov, A. P., Middleton, E. M., Huemmrich, K. F., Yoshida, Y., and Frankenberg, C.: Global monitoring of terrestrial chlorophyll fluorescence from moderate-spectral-resolution near-infrared satellite measurements: methodology, simulations, and ap- plication to GOME-2, Atmos. Meas. Tech., 6, 2803-2823, https://doi.org/10.5194/amt-6-2803-2013, 2013.

Krotkov, N. A., Lamsal, L. N., Celarier, E. A., Swartz, W. H., Marchenko, S. V., Bucsela, E. J., Chan, K. L., Wenig, M., and Zara, M.: The version $3 \mathrm{OMI} \mathrm{NO}_{2}$ standard product, Atmos. Meas. Tech., 10, 3133-3149, https://doi.org/10.5194/amt10-3133-2017, 2017.

Lacan, A. and Lang, R.: Investigation on GOME-2 throughput degradation, Final report, EUM/LEO/REP/09/0732 Issue 1.1, 16 July, 2011.

Lamsal, L. N., Duncan, B. N., Yoshida, Y., Krotkov, N. A., Pickering, K. E., Streets, D. G., and Lu, Z.: U.S. $\mathrm{NO}_{2}$ trends (2005-2013): EPA Air Quality System (AQS) data versus improved observations from the Ozone Monitoring Instrument (OMI), Atmos. Environ., 110, 130-143, https://doi.org/10.1016/j.atmosenv.2015.03.055, 2015.

Leue, C., Wenig, M., Wagner, T., Platt, U., and Jähne, B.: Quantitative analysis of $\mathrm{NO}_{x}$ emissions from GOME satellite image sequences, J. Geophys. Res., 106, 5493-5505, 2001.

Levelt, P. F., Van den Oord, G. H. J., Dobber, M. R., Mälkki, A., Visser, H., De Vries, J., Stammes, P., Lundell, J. O. V, and Saari, H.: The Ozone Monitoring Instrument, IEEE T. Geosci. Remote, 44, 1093-1101, 2006b.

Liu, S., Valks P., Pinardi, G., De Smedt, I., Yu, H., and Beirle, S.: An Improved total and tropospheric $\mathrm{NO}_{2}$ column retrieval for GOME-2, Proc. Living Planet Symposium 2016, Prague, Czech Republic, 9-13 May, 2016.

Lorente, A., Folkert Boersma, K., Yu, H., Dörner, S., Hilboll, A., Richter, A., Liu, M., Lamsal, L. N., Barkley, M., De Smedt, I., Van Roozendael, M., Wang, Y., Wagner, T., Beirle, S., Lin, J.T., Krotkov, N., Stammes, P., Wang, P., Eskes, H. J., and Krol, M.: Structural uncertainty in air mass factor calculation for $\mathrm{NO}_{2}$ and HCHO satellite retrievals, Atmos. Meas. Tech., 10, 759-782, https://doi.org/10.5194/amt-10-759-2017, 2017.

Marchenko, S., Krotkov, N. A., Lamsal, L. N., Celarier, E. A., Swartz, W. H., and Bucsela, E. J.: Revising the slant column density retrieval of nitrogen dioxide observed by the Ozone Monitoring Instrument, J. Geophys. Res.-Atmos., 120, 5670-5692, https://doi.org/10.1002/2014JD022913, 2015.

McPeters, R. D., Frith, S., and Labow, G. J.: OMI total column ozone: extending the long-term data record, Atmos. Meas. Tech., 8, 4845-4850, https://doi.org/10.5194/amt-8-4845-2015, 2015.

Millet, D. B., Jacob, D. J., Boersma, K. F., Fu, T.-M., Kurosu, T. P., Chance, K., Heald, C. L., and Guenther, A.: Spatial distribution of isoprene emissions from North America derived from formaldehyde column measurements by the OMI satellite sensor, J. Geophys. Res., 113, D02307, https://doi.org/10.1029/2007JD008950, 2008.

Miyazaki, K., Eskes, H., Sudo, K., Boersma, K. F., Bowman, K., and Kanaya, Y.: Decadal changes in global surface $\mathrm{NO}_{x}$ emissions from multi-constituent satellite data assimilation, Atmos. Chem. Phys., 17, 807-837, https://doi.org/10.5194/acp-17-8072017, 2017.

Muller, J.-P., Kharbouche, S., Gobron, N., Scanlon, T., Govaerts, Y., Danne, O., Schultz, J., Lattanzio, A., Peters, E., De Smedt I., Beirle, S., Lorente, A., Coheur, P. F., George, M., Wagner, T., Hilboll, A., Richter, A., Van Roozendael, M., and Boersma, K. F.: Recommendations (scientific) on best practices for retrievals for Land and Atmosphere ECVs (QA4ECV Deliverable 4.2 version 
1.0), 186 pp., available at: http://www.qa4ecv.eu/sites/default/ files/D4.2.pdf (last access: 12 April 2018), 2016.

Munro, R., Lang, R., Klaes, D., Poli, G., Retscher, C., Lindstrot, R., Huckle, R., Lacan, A., Grzegorski, M., Holdak, A., Kokhanovsky, A., Livschitz, J., and Eisinger, M.: The GOME2 instrument on the Metop series of satellites: instrument design, calibration, and level 1 data processing - an overview, Atmos. Meas. Tech., 9, 1279-1301, https://doi.org/10.5194/amt-9-12792016, 2016.

Peters, E., Wittrock, F., Richter, A., Alvarado, L. M. A., Rozanov, V. V., and Burrows, J. P.: Liquid water absorption and scattering effects in DOAS retrievals over oceans, Atmos. Meas. Tech., 7, 4203-4221, https://doi.org/10.5194/amt-7-4203-2014, 2014.

Platt, U.: Air Monitoring by Differential Optical Absorption Spectroscopy, Encyclopedia of Analytical Chemistry, 1-28, 2017.

Pommereau, J.-P. and Goutail, F.: $\mathrm{O}_{3}$ and $\mathrm{NO}_{2}$ ground-based measurements by visible spectrometry during arctic winter and spring 1988, Geophys. Res. Lett., 15, 891-894, 1988.

Press, W. H., Teukolsky, S. A., Vetterling, W. T., and Flannery, B. P.: Numerical recipes in Fortran 77: The art of scientific computing, 2nd edn., Vol. 1 of Fortran Numerical Recipes, 1997.

Puķīe, J., Kühl, S., Deutschmann, T., Platt, U., and Wagner, T.: Extending differential optical absorption spectroscopy for limb measurements in the UV, Atmos. Meas. Tech., 3, 631-653, https://doi.org/10.5194/amt-3-631-2010, 2010.

Richter, A.: Absorptionsspektroskopische Messungen stratosphärischer Spurengase über Bremen, $53^{\circ} \mathrm{N}, \mathrm{PhD}-\mathrm{Thesis}$, University of Bremen, 1997.

Richter, A., Begoin, M., Hilboll, A., and Burrows, J. P.: An improved $\mathrm{NO}_{2}$ retrieval for the GOME-2 satellite instrument, Atmos. Meas. Tech., 4, 1147-1159, https://doi.org/10.5194/amt-41147-2011, 2011.

Richter, A., Wittrock F., and Burrows, J. P.: Development of an OClO Slant Column Product for the GOME-2 Sensors, EGU General Assembly, Vienna, Austria, 2016.

Sanders, A. F., Verstraeten, W. W., Kooreman, M. L., Van Leth, T. C., Beringer, J., and Joiner, J.: Spaceborne Sun-Induced Vegetation Fluorescence Time Series from 2007 to 2015 Evaluated with Australian Flux Tower Measurements, Remote Sens., 8, 895, https://doi.org/10.3390/rs8110895, 2016.

Schenkeveld, V. M. E., Jaross, G., Marchenko, S., Haffner, D., Kleipool, Q. L., Rozemeijer, N. C., Veefkind, J. P., and Levelt, P. F.: In-flight performance of the Ozone Monitoring Instrument, Atmos. Meas. Tech., 10, 1957-1986, https://doi.org/10.5194/amt-10-1957-2017, 2017.

Sillman, S., Logan, J. A., and Wofsy, S. C.: The sensitivity of ozone to nitrogen oxides and hydrocarbons in regional ozone episodes, J. Geophys. Res., 95, 1837-1851, https://doi.org/10.1029/JD095iD02p01837, 1990.
Spurr, R.: LIDORT and VLIDORT: Linearized pseudo-spherical scalar and vector discrete ordinate radiative transfer models for use in remote sensing retrieval problems, in: Light Scattering Reviews, 3, eited by: Kokhanovsky, A., Springer, 2008.

Sun, K., Liu, X., Huang, G., González Abad, G., Cai, Z., Chance, K., and Yang, K.: Deriving the slit functions from OMI solar observations and its implications for ozone-profile retrieval, Atmos. Meas. Tech., 10, 3677-3695, https://doi.org/10.5194/amt10-3677-2017, 2017.

Valks, P., Pinardi, G., Richter, A., Lambert, J.-C., Hao, N., Loyola, D., Van Roozendael, M., and Emmadi, S.: Operational total and tropospheric $\mathrm{NO}_{2}$ column retrieval for GOME-2, Atmos. Meas. Tech., 4, 1491-1514, https://doi.org/10.5194/amt-4-1491-2011, 2011.

van Geffen, J. H. G. M., Boersma, K. F., Van Roozendael, M., Hendrick, F., Mahieu, E., De Smedt, I., Sneep, M., and Veefkind, J. P.: Improved spectral fitting of nitrogen dioxide from OMI in the 405-465 nm window, Atmos. Meas. Tech., 8, 1685-1699, https://doi.org/10.5194/amt-8-1685-2015, 2015.

Veihelmann, B. and Kleipool, Q.: Reducing Along-Track Stripes in OMI-Level 2 Products, TN-OMIE-KNMI-785, 24 pp., 2006.

Verstraeten, W. W., Neu, J. L., Williams, J. E., Bowman, K. W., Worden, J. R., and Boersma, K. F.: Rapid increases in tropospheric ozone production and export from China, Nat. Geosci., 8, 690-695, https://doi.org/10.1038/ngeo2493, 2015.

Voors, R., Dobber, M., Dirksen, R., and Levelt, P.: Method of calibration to correct for cloud-induced wavelength shifts in the Aura satellite's Ozone Monitoring Instrument, Appl. Opt., 45, 36523658, 2006.

Vountas, M., Rozanov, V., and Burrows, J.: Ring effect: Impact of rotational Raman scattering on radiative transfer in Earth's atmosphere, J. Quant. Spectrosc. Ra., 60, 943-961, https://doi.org/10.1016/S0022-4073(97)00186-6, 1998.

Wenig, M.: Satellite Measurement of Long-Term Global Tropospheric Trace Gas Distributions and Source Strengths - Algorithm Development and Data Analysis, part of the German Research Foundation (DFG) research unit "Image Sequence Analysis to Investigate Dynamic Processes”, PhD Thesis, 2001.

Zhu, L., Jacob, D. J., Keutsch, F. N., Mickley, L. J., Scheffe, R., Strum, M., González Abad, G., Chance, K., Yang, K., Rappenglück, B., Millet, D. B., Baasandorj, M., Jaeglé, L., and Shah, V.: Formaldehyde (HCHO) As a Hazardous Air Pollutant: Mapping Surface Air Concentrations from Satellite and Inferring Cancer Risks in the United States, Environ. Sci. Technol., 51, 5650-5657, 2017. 